\title{
The Energetics of Southern Ocean Upwelling
}

\author{
ANDREW MCC. HOGG \\ Research School of Earth Sciences, and ARC Centre of Excellence for Climate System Science, Australian \\ National University, Canberra, Australian Capital Territory, Australia \\ PAUl SPENCE \\ Climate Change Research Centre, and ARC Centre of Excellence for Climate System Science, University of New \\ South Wales, Sydney, New South Wales, Australia \\ OLEG A. SAENKO \\ Canadian Centre for Climate Modelling and Analysis, Victoria, British Columbia, Canada \\ STEPHANIE M. DOWNES \\ Antarctic Climate and Ecosystems Cooperative Research Centre, University of Tasmania, Hobart, Tasmania, Australia
}

(Manuscript received 27 July 2016, in final form 31 October 2016)

\begin{abstract}
The ocean's meridional overturning circulation is closed by the upwelling of dense, carbon-rich waters to the surface of the Southern Ocean. It has been proposed that upwelling in this region is driven by strong westerly winds, implying that the intensification of Southern Ocean winds in recent decades may have enhanced the rate of upwelling, potentially affecting the global overturning circulation. However, there is no consensus on the sensitivity of upwelling to winds or on the nature of the connection between Southern Ocean processes and the global overturning circulation. In this study, the sensitivity of the overturning circulation to changes in Southern Ocean westerly wind stress is investigated using an eddy-permitting ocean-sea ice model. In addition to a suite of standard circulation metrics, an energy analysis is used to aid dynamical interpretation of the model response. Increased Southern Ocean wind stress enhances the upper cell of the overturning circulation through creation of available potential energy in the Southern Hemisphere, associated with stronger upwelling of deep water. Poleward shifts in the Southern Ocean westerlies lead to a complicated transient response, with the formation of bottom water induced by increased polynya activity in the Weddell Sea and a weakening of the upper overturning cell in the Northern Hemisphere. The energetic consequences of the upper overturning cell response indicate an interhemispheric connection to the input of available potential energy in the Northern Hemisphere.
\end{abstract}

\section{Introduction}

The circulation of the Southern Ocean is characterized by strong eastward zonal flow [the Antarctic Circumpolar Current (ACC)]. The baroclinic component of the ACC is associated with isopycnal layers that slope up toward the surface in the south, thereby connecting the deep and abyssal ocean with surface waters (Morrison et al. 2015). This isopycnal slope is maintained in part by the strong westerly wind stress at the surface and provides a conduit by which deep, dense water can travel to the surface with minimal energetic cost (Toggweiler and Samuels

Corresponding author e-mail: Andrew Hogg, andy.hogg@anu.edu.au
1998). Such an upward transport is considered to be an essential component of the global meridional overturning circulation (MOC; Marshall and Speer 2012). The Southern Ocean therefore seems likely to be a key location where dense water, formed in the North Atlantic and on the coastal fringes of Antarctica, returns to the surface.

Southern Ocean upwelling may directly influence the global carbon cycle via ventilation of deep, old, carbonrich water. Changes in the Southern Ocean ventilation rate are therefore proposed to have been responsible for past changes in global climate and the carbon cycle (e.g., Toggweiler et al. 2006; Anderson et al. 2009), implying that the present carbon cycle could also be modified by 
changes in Southern Ocean upwelling (Le Quéré et al. 2007). Given the role of westerly winds in controlling this upwelling, it is possible that changes in Southern Ocean winds will have ramifications for the global carbon cycle.

However, there are a number of factors that complicate the hypothesis of wind-driven modifications of the overturning circulation and carbon cycle. First, the role of eddies in the Southern Ocean act to counteract variations in the wind-driven circulation (Marshall and Radko 2003) via a process known as eddy compensation (Viebahn and Eden 2010). While there is strong evidence that eddies can only compensate approximately half of the wind-driven changes (Meredith et al. 2012; Morrison and Hogg 2013), eddy compensation implies that climate models may have overestimated the sensitivity of upwelling to wind stress changes (Gent 2016). More recently, it has become apparent that, in addition to transient eddies, there is likely a role for standing meanders (i.e., the nonzonality of the mean flow) in controlling the adjustment process (Abernathey and Cessi 2014; Bishop et al. 2016), although this component may be eliminated with careful averaging procedures (Viebahn and Eden 2012).

A second complication is that there is an interhemispheric component to the upper cell of the MOC (Wolfe and Cessi 2011). Thus, a large fraction of the water supplied for Southern Ocean upwelling is derived from the North Atlantic [the northern branch of the MOC, generally known as the Atlantic meridional overturning circulation (AMOC)]. The extent to which the MOC is controlled by Northern Hemisphere or Southern Hemisphere processes remains an active topic of debate (Delworth and Zeng 2008; Bishop et al. 2016; Gent 2016). For example, it has recently been proposed that a reduction in Southern Ocean winds transfers upwelling to the tropical Pacific Ocean, without any impact on the MOC in the Northern Hemisphere (Jochum and Eden 2015).

Third, the upper MOC is also sensitive to local buoyancy forcing in the Southern Ocean (Morrison et al. 2011) or alternatively the surface boundary condition used in ocean models (Abernathey et al. 2011). Furthermore, the lower, or abyssal, overturning cell is also a strong function of surface buoyancy fluxes that control the rate of dense water formation around Antarctica (Snow et al. 2016). This dense water sinks to fill the abyssal depths of the ocean with Antarctic Bottom Water. The surface buoyancy fluxes that drive the abyssal overturning are largest in regions of sea ice production or open water (polynyas) close to the Antarctic coast where the insulation provided by sea ice is minimal (Tamura et al. 2016) and may therefore also depend on local wind stress variations that act to keep polynyas free of ice. However, most climate models form bottom water through open-ocean polynyas that connect directly to the deep ocean (Heuzé et al. 2015). Furthermore, the lower MOC may also be sensitive to interior mixing (Nikurashin and Ferrari 2013), which may be partly controlled by the wind stress-induced eddy field (Stanley and Saenko 2014). Thus, both mechanical and diabatic forcing conspire to control both the upper and lower overturning circulation in a manner that has, thus far, eluded comprehensive explanation.

In this paper, we use eddy-permitting simulations of the global ocean circulation to better understand the response of the MOC to wind stress changes over the Southern Ocean. We analyze these simulations from an energetic perspective, focusing on the evolution of available potential energy of the model, as outlined in section 2 below. We then aim to connect this energetic diagnosis with the overturning circulation, using a combination of the latitude-density (often called the residual) overturning streamfunction and the depth-density streamfunction (Nurser and Lee 2004; Nycander et al. 2007; Zika et al. 2013; see section 2d). The model is described in section 3 , and the results are described in section 4 . We discuss the implications of these results in section 5 .

\section{Energy}

In this section, we outline the general framework used to analyze the energy budget in this paper. The focus of this energy budget is the total mechanical energy, defined as the sum of the kinetic energy (KE) and available potential energy (APE), and in particular the exchange between these two reservoirs (Hughes et al. 2009). The details of how energetic quantities are estimated from model diagnostics are outlined in the appendix.

\section{a. Kinetic energy budget}

We define the kinetic energy (per unit mass, averaged over the domain $V$ ) to be

$$
E_{k}=\frac{1}{2 V} \int_{V}\left(u^{2}+v^{2}\right) d V,
$$

where $u$ and $v$ are the horizontal velocities (noting that vertical velocity does not contribute to the $\mathrm{KE}$ budget in a hydrostatic model), and $V$ is the volume of the domain, meaning that the units of $\mathrm{KE}$ are joules per kilogram. Following Dijkstra et al. (2014), the KE tendency equation for an ocean model can be written as 


$$
\frac{d E_{k}}{d t}=\Phi_{\tau}-\Phi_{z}-\varepsilon
$$

where the terms on the right-hand side are the power input (watts per kilogram) owing to wind stress, $\tau=\left(\tau^{x}, \tau^{y}\right)$, integrated over the upper surface of the domain $S$;

$$
\Phi_{\tau}=\frac{1}{\rho_{0} V} \int_{S}\left(u \tau^{x}+v \tau^{y}\right) d S,
$$

where $\rho_{0}$ is a constant reference density; and the conversion from kinetic to potential energy

$$
\Phi_{z}=\frac{g}{\rho_{0} V} \int_{V} \rho w d V
$$

where $w$ is the vertical component of velocity, and the viscous dissipation is $\varepsilon$ (which includes interior dissipation as well as boundary drag, neither of which are explicitly calculated here). Note that it is trivial and often informative to split kinetic energy into a time mean and a transient, or "eddy," component.

\section{b. Potential energy budget}

The gravitational potential energy (GPE) is defined as

$$
E_{p}=\frac{g}{\rho_{0} V} \int_{V} \rho z d V
$$

where $g$ is the acceleration due to gravity, and $z$ is the vertical coordinate, defined to be negative below the surface; thus, $E_{p}$ is always negative (highlighting the arbitrary nature of GPE). In the calculations in this paper, we approximate the density $\rho$ to be the potential density at $2000 \mathrm{~m}$, or $\sigma_{2}$, based on the advice of Ilicak et al. (2012) and Saenz et al. (2015). In this approximation, nonlinear effects such as cabbeling, which can create density in the ocean interior, are framed as a source of available potential energy and can, in principle, be calculated explicitly (e.g., Urakawa et al. 2013).

APE is calculated as the potential energy relative to a reference state, defined as the hypothetical state to which the fluid would adiabatically relax in the absence of forcing and mixing. The reference state is by definition stably stratified, with no lateral variations in density. To define this state, we calculate a quantity $z_{*}(\rho)$, following Winters et al. (1995):

$$
z_{*}(\mathbf{x}, t) \equiv \frac{1}{A} \int_{V} H\left[\rho\left(\mathbf{x}^{\prime}, t\right)-\rho(\mathbf{x}, t)\right] d V^{\prime},
$$

which represents the geopotential height of a fluid parcel in the reference state, $H$ being the Heaviside function, and the primed quantities within the integral are dummy variables. This expression is not trivial to evaluate in a complex domain, and we have made no attempt to account for the APE stored in marginal seas such as the Arctic and Mediterranean. Based on Stewart et al. (2014), we should cap these basins at the sill depth and exclude deep water formed in marginal seas from our analysis.

Once we know $z_{*}$ we can calculate background PE (BPE), which is the GPE of the reference state:

$$
E_{b}=\frac{g}{\rho_{0} V} \int_{V} \rho z_{*} d V
$$

Since BPE represents the minimum possible potential energy state of the fluid, the difference between GPE and BPE is the maximum energy available to drive motion or the APE:

$$
E_{a}=E_{p}-E_{b}=\frac{g}{\rho_{0} V} \int_{V} \rho\left(z-z_{*}\right) d V .
$$

As shown in the appendix, we write the APE tendency as

$$
\frac{d E_{a}}{d t}=\Phi_{z}+\Phi_{b}+\Phi_{c}+\Phi_{d}
$$

The individual terms in this tendency equation can be considered as follows:

- The term $\Phi_{z}$ is the rate of conversion of KE to APE as given by Eq. (4). It literally represents the net vertical flux of density by the resolved flow and hence is inextricably connected to the overturning circulation.

- The term $\Phi_{b}$ is the influence of surface buoyancy fluxes on APE:

$$
\Phi_{b}=\frac{-g}{\rho_{0} V} \int_{S} \delta_{z}^{1}\left(z^{1}-z_{*}^{1}\right) Q_{\rho} d S,
$$

where $\delta_{z}$ is the vertical grid size, $Q_{\rho}$ is the density forcing through the upper surface of the ocean $S$, and ${ }^{1}$ indicates quantities evaluated within the surface grid cell. Surface fluxes that act to increase density $\left(Q_{\rho}<0\right)$ in regions where fluid is dense $\left(z_{*}^{1} \ll z^{1}\right)$ generate APE from BPE, resulting in a positive $\Phi_{b}$ (Hughes et al. 2009). This expression is dominated by the $\int_{S}-\delta_{z}^{1} z_{*}^{1} Q_{\rho} d S$ component, as $\int_{S} \delta_{z}^{1} z^{1} Q_{\rho} d S \approx 0$ when surface forcing is balanced $\left(\int_{S} Q_{\rho} d S \approx 0\right)$.

- The term $\Phi_{c}$ is the convective term:

$$
\Phi_{c}=\frac{g}{\rho_{0} V} \int_{V}\left(z-z_{*}\right)\left[\rho_{t}\right]_{c} d V,
$$

where $\left[\rho_{t}\right]_{c}$ is the rate of change of density due to the convective adjustment parameterization. Convective 
adjustment takes dense water close to the surface $\left(z-z_{*} \gg 0\right)$ and mixes it vertically with deeper, less dense water. Thus, it is a direct sink of APE. In a real fluid, this convection releases APE to KE; however, in a hydrostatic ocean model APE is artificially removed by convective adjustment without generating $\mathrm{KE}$ and thus lacks the direct connection to the overturning circulation.

- The term $\Phi_{d}$ is the diffusive contribution to APE. It is written as

$$
\Phi_{d}=\frac{g}{\rho_{0} V} \int_{V}\left(z-z_{*}\right)\left[\rho_{t}\right]_{d} d V
$$

where $\left[\rho_{t}\right]_{d}$ is the rate of change of density due to diffusive processes diagnosed from the model. This expression creates GPE (some of which goes to APE) by lifting the center of mass of the fluid in the domain; it is implied that the "source" of this energy is unresolved turbulence powered by mechanical sources, such as tidally driven mixing. It can also be a sink of APE through irreversible mixing (Hughes et al. 2009), thereby counteracting $\Phi_{b}$ and contributing to BPE.

This energy budget is shown schematically in Fig. 1, where we have included the BPE reservoir, and schematically indicated the fate of convective and diffusive fluxes.

\section{c. APE density}

One drawback with the APE formulation is that the integrand of Eq. (8) is not positive definite [unlike the integrand of Eq. (1)], complicating the regional diagnosis of APE. To overcome this difficulty we now define a positive definite APE density (Holliday and McIntyre 1981). Recent attempts to outline the utility of APE density include Roullet and Klein (2009), Molemaker and McWilliams (2010), and Winters and Barkan (2013). Here, we follow the notation of Winters and Barkan (2013), but note that each of these three implementations are physically equivalent. We define APE density $\mathscr{E}_{a}$ to be

$$
\mathscr{E}_{a}(x, y, z, t) \equiv\left(z-z_{*}\right)\left[\rho-\bar{\rho}\left(z, z_{*}\right)\right] \geq 0,
$$

where

$$
\bar{\rho}\left(z, z_{*}\right) \equiv \frac{1}{\left(z-z_{*}\right)} \int_{z_{*}}^{z} \rho\left(z_{*}^{\prime}\right) d z_{*}^{\prime}
$$

is the average value of $\rho$ in the interval between $z$ and $z_{*}$. APE density is therefore composed of two terms: the energetic cost or benefit of moving fluid parcels to their

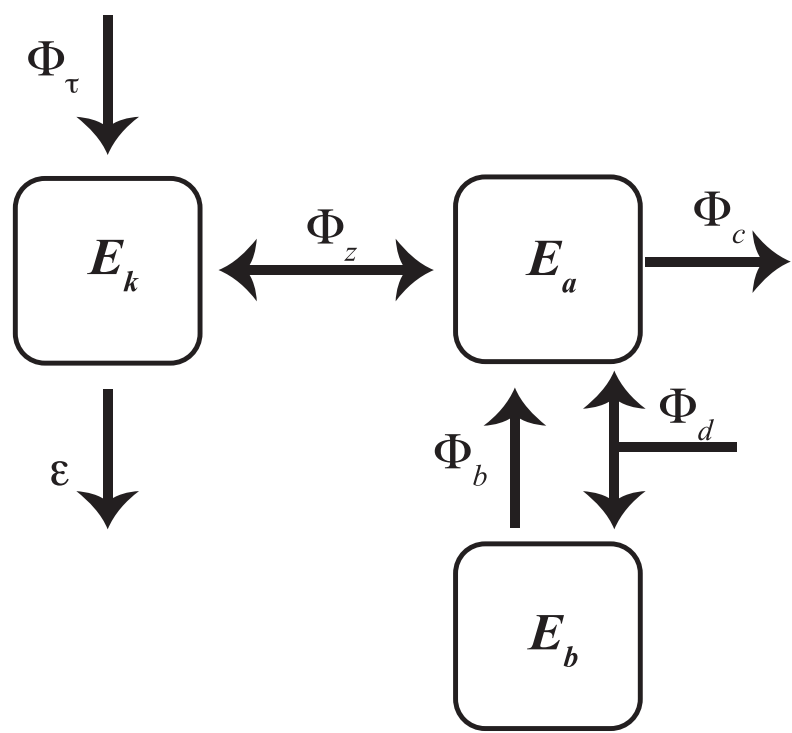

FIG. 1. Energetics of an ocean model, adapted from Hughes et al. (2009). Mechanical energy is defined as the sum of the kinetic energy $E_{k}$ and the available potential energy $E_{a}$. Mechanical forcing of kinetic energy $\Phi_{\tau}$ and conversion of background to available potential energy by surface buoyancy forcing $\Phi_{b}$ are the primary sources of mechanical energy, with dissipation $\varepsilon$ and parameterized convection $\Phi_{c}$ acting as sinks of energy. The diffusive contribution $\Phi_{d}$ can be a source or a sink; $\Phi_{z}$ is the conversion between $E_{k}$ and $E_{a}$ and is closely linked with the overturning circulation.

reference depth $\left[\left(z-z_{*}\right) \rho\right]$ and the compensating adjustment of all other parcels in a volume-conserving system (Winters and Barkan 2013). Where lateral variations in density are small, the definition of $\mathscr{E}_{a}$ reverts to the quasigeostrophic approximation for APE (Molemaker and McWilliams 2010). Most importantly, it can be shown (Winters and Barkan 2013) that $\mathscr{E}_{a}$ is positive definite and that upon integration over the volume it is equivalent to APE, allowing us to replace Eq. (8) with

$$
E_{a}=\frac{g}{\rho_{0} V} \int_{V} \mathscr{E}_{a} d V
$$

Thus, APE density can be used to analyze the regional variations of APE through a positive definite term. It is also possible to derive a tendency equation for $\mathscr{E}_{a}$, which has a similar structure to Eq. (9), including interior buoyancy flux and diabatic contributions (Tailleux 2013). The APE density diagnostic was used by Hogg et al. (2013) to understand the energetic response of the AMOC to freshwater flooding using an idealized sector model. The present study is the first where this APE density diagnostic is used in a global eddy-permitting model.

\section{d. Overturning diagnostics}

To diagnose overturning circulation in the Southern Ocean, we need to calculate the temporal and zonal 
average of the flow. An Eulerian zonal average of the meridional flow yields a strong Deacon cell (Döös and Webb 1994), which bears little resemblance to tracer pathways. We therefore analyze the physical circulation in latitude-density space, which can be written [following Zika et al. (2013)] as

$$
\Psi_{y \rho}=-\frac{1}{\Delta t} \int_{t_{1}}^{t_{2}} \iint_{\rho^{\prime} \leq \rho} v(x, y, z, t) d z d x d t,
$$

where $\Delta t=t_{2}-t_{1}$ is the time interval over which averaging is performed. This diagnostic is computed online during the simulation.

The depth-density streamfunction, again following Zika et al. (2013), is written as

$$
\Psi_{z \rho}=-\frac{1}{\Delta t} \int_{t_{1}}^{t_{2}} \iint_{\rho^{\prime} \leq \rho} w(x, y, z, t) d x d y d t .
$$

As pointed out by Nycander et al. (2007), this streamfunction essentially isolates the regional contribution of the conversion of KE to APE, defined as $\Phi_{z}$ above, and thus provides a natural link between the energetic analysis and overturning diagnostics.

\section{Model simulations}

We show results from four simulations using a global ocean-sea ice model with mesoscale eddy-permitting horizontal resolution. The model is based on the Geophysical Fluid Dynamics Laboratory (GFDL) CM2.5 fully coupled climate model (Delworth et al. 2012; Griffies et al. 2015). The model has a $1 / 4^{\circ}$ Mercator horizontal resolution with $\sim 11-\mathrm{km}$ grid spacing at $65^{\circ} \mathrm{S}$ (similar to the Rossby radius there) and resolves the majority of the Southern Ocean's eddy kinetic energy. The ocean model has 50 vertical levels and is coupled to the GFDL Sea Ice Simulator model. Sea surface salinity is restored to seasonally varying climatology on a 60-day time scale. The atmospheric state is prescribed and converted to ocean surface fluxes by bulk formulas; consequently, the model does not resolve all air-sea feedbacks. The atmospheric forcing is derived from version 2 of the Co-ordinated Ocean-Ice Reference Experiments-Normal Year Forcing (CORE-NYF) reanalysis data (Large and Yeager 2009). CORE-NYF provides a 1-yr climatological-mean atmospheric state at 6-h intervals.

The model is spun up for $500 \mathrm{yr}$ under CORE-NYF forcing, and then we branch off a series of step-change perturbations wherein the near-surface Southern Ocean winds are modified. The idealized wind perturbations are based on the observed positive trend in the southern

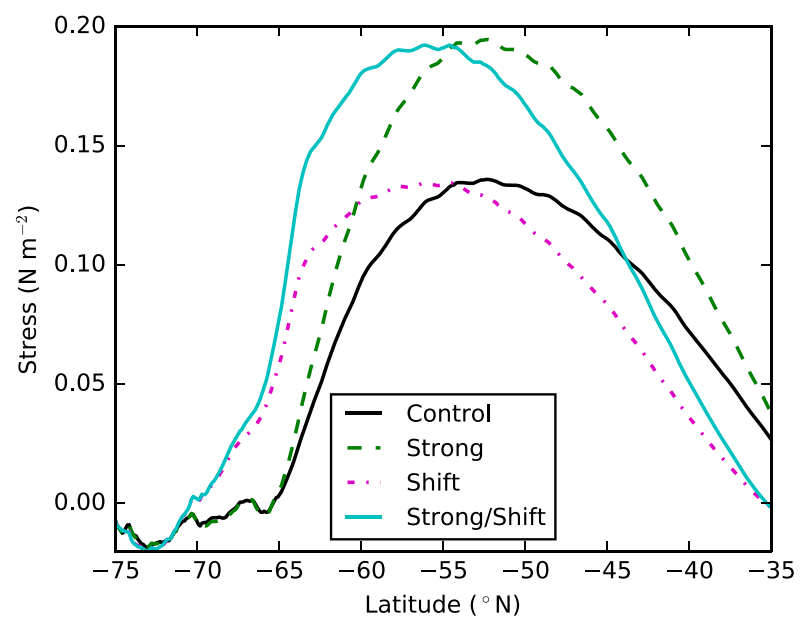

FIG. 2. Mean eastward wind stress over the Southern Ocean from the last decade of each of the four different simulations.

annular mode associated with strengthened and polewardshifted Southern Hemisphere midlatitude westerly winds since the 1950s (Thompson and Solomon 2002). This trend is consistently projected to persist through the twenty-first century due to continued anthropogenic forcing (Zheng et al. 2013). The zonal-mean wind stress from each simulation is shown in Fig. 2, with the four different simulation denoted as follows:

Control: The reference case that has equilibrated for $500 \mathrm{yr}$.

Strong: The Southern Ocean winds are increased in magnitude by $15 \%$.

Shift: The Southern Ocean winds are uniformly shifted $4^{\circ} \mathrm{S}$.

Strong/shift: Poleward-intensifying Southern Ocean winds (i.e., strong + shift).

The wind perturbations are applied to the CORE-NYF $10-\mathrm{m}$ winds between $25^{\circ}$ and $70^{\circ} \mathrm{S}$ with smoothing within $5^{\circ}$ latitude of the perturbation boundaries. The perturbation simulations are run for $50 \mathrm{yr}$ and anomalies determined by differencing them from the concomitantly extended CNTRL simulation. The idealized wind perturbation scenarios were guided by an assessment of the late-twenty-first-century change in Southern Ocean zonal winds induced by "business as usual" anthropogenic forcing (RCP8.5) in 32 climate models from phase 5 of the Coupled Model Intercomparison Project (CMIP5; Spence et al. 2014).

\section{Results}

Standard metrics of the control simulation are shown in Fig. 3. The figure shows time means of model sea 
(a)

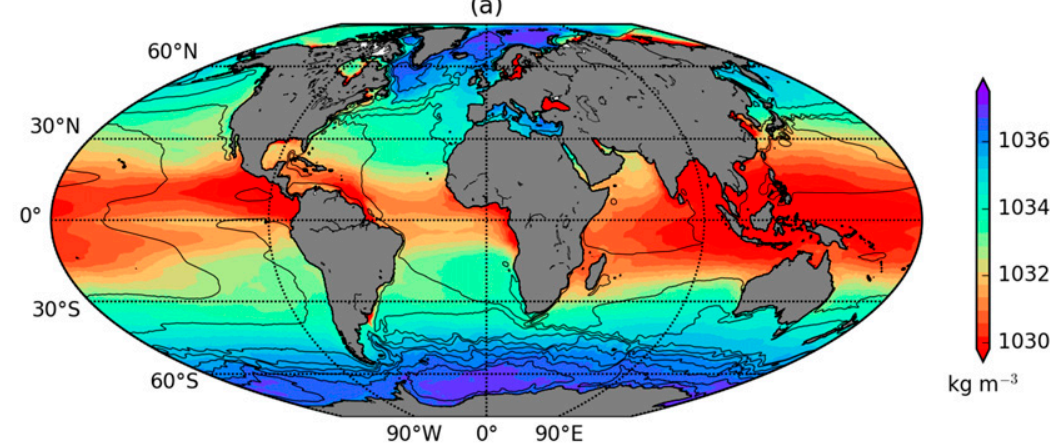

(b)

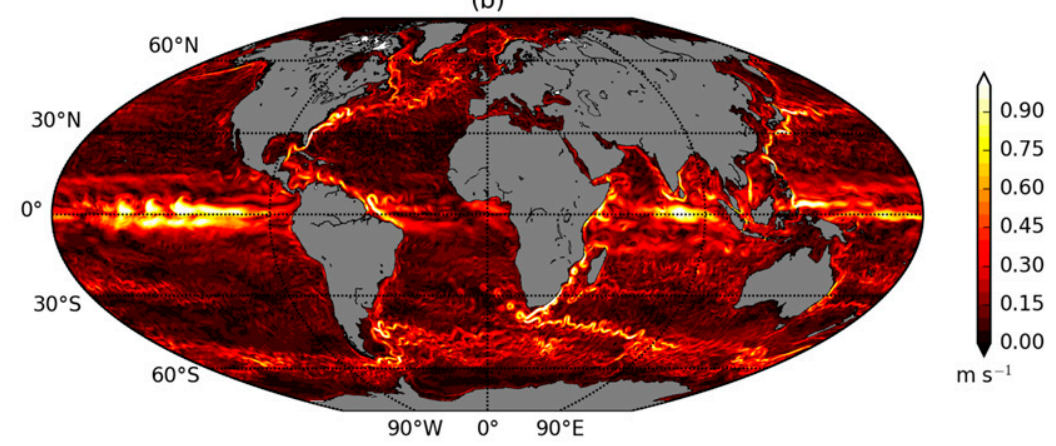

(c)

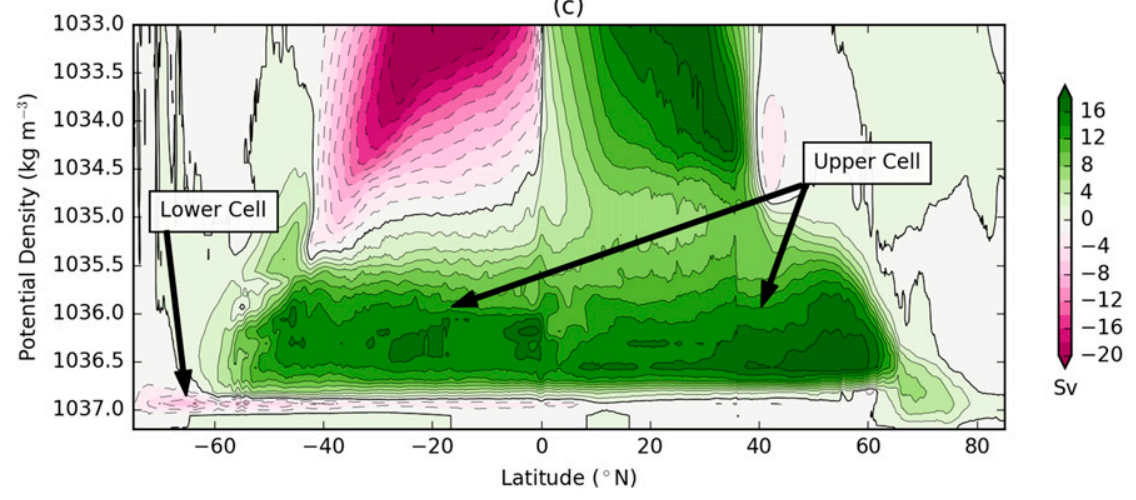

FIG. 3. Diagnostics from the control simulation. (a) Annually averaged potential density $\sigma_{2}$ at the surface, overlaid with mean sea surface height contours (contour interval $0.3 \mathrm{~m}$ ); (b) snapshot of model absolute velocity; and (c) 50-yr average latitude-density streamfunction in density space.

surface height and surface potential density (contours and colors, respectively, in Fig. 3a) to illustrate the expected patterns of midlatitude gyres, the ACC, and higher surface density in polar regions. Western boundary currents and Southern Ocean flow-topography interactions are well resolved in the mean flow in this model (compared with coarse-resolution ocean models). The structure of these currents is highlighted by a snapshot of surface absolute velocity (Fig. 3b), with the fine structure of eddies and jets (especially toward the polar regions) and tropical instability waves in the tropical Pacific Ocean captured. The model overturning circulation $\Psi_{y \rho}$ (Fig. 3c) is calculated and displayed in latitude-density space to obtain the best representation of Southern Ocean upwelling. Here, the strong subtropical cells at lower density are truncated to concentrate on the deep overturning cells. The upper MOC is shown in green in the density ranges $1035.5-1036.8 \mathrm{~kg} \mathrm{~m}^{-3}$, while the lower MOC centered on $1037 \mathrm{~kg} \mathrm{~m}^{-3}$ is shown in magenta. The MOC in this model has a strong interhemispheric component. Dense water formed in the North Atlantic and Arctic Oceans crosses the equator in a near-adiabatic fashion (at $\sigma_{2} \approx 1036.7 \mathrm{~kg} \mathrm{~m}^{-3}$ ) and outcrops at the surface in the Southern Ocean. This cell is the primary focus of the 
present paper. The lower cell in this model, as noted above, is relatively weak $\left[\sim 5 \mathrm{~Sv}\left(1 \mathrm{~Sv} \equiv 10^{6} \mathrm{~m}^{3} \mathrm{~s}^{-1}\right)\right.$; less than half that observed by Lumpkin and Speer (2007)] due to the poor representation of near-coastal processes in the Antarctic region where the dense water that drives the abyssal overturning cell is formed (Snow et al. 2016).

An overview of the model's response to Southern Ocean wind stress perturbations is shown in Fig. 4. The strengthening of Southern Ocean winds (green dashed line) acts to enhance the upper MOC (measured at $26^{\circ} \mathrm{N}$ ) within a decade of the wind perturbation being switched on (Fig. 4a). This response is consistent with our expectations from the effect of wind-driven upwelling in the Southern Ocean. The strengthening experiment is also associated with a modest increase in ACC transport (Fig. 4c), while the lower MOC decreases initially (Fig. 4b) before slowly building back up to the control case.

The shifted wind case (magenta dashed line) is less transparent. First, it results in a measurable decrease in the upper MOC (Fig. 4a), which is offset by an increase in the lower MOC (Fig. 4b). The lower cell response is largely due to an open-ocean polynya in the Weddell Sea, which is commonly generated by wind stress perturbations in models (Cheon et al. 2014). This polynya can be recognized in the model mixed layer depth (shown for years 510-520 in Fig. 5) where the shift case generates mixed layers $\sim 2000 \mathrm{~m}$ deep in the Weddell Sea region. The polynya forms dense water in the open ocean, which sinks to the deep ocean and drives a stronger abyssal circulation. The enhanced lower MOC is directly linked to the stronger zonal transport (Fig. 4c), as predicted in previous studies (e.g., Gent et al. 2001; Howard et al. 2015). The reduction in the upper cell is mostly likely due to a geometric effect (e.g., Lauderdale et al. 2013) in which poleward shifting of winds reduces the total area of westerly wind stress forcing, leading to a weaker effective wind stress and lower kinetic energy input.

When winds are both shifted and intensified (solid cyan line), the geometric effect is partially offset by stronger winds, meaning that the upper MOC strength at $26^{\circ} \mathrm{N}$ is similar to the control case (Fig. 4a). However, the open-ocean polynya in the Weddell Sea further intensifies in this simulation (Fig. 5d), meaning that the lower cell (Fig. 4b) and ACC (Fig. 4c) response is even larger. This polynya is not the subject of the present paper, but in the detailed analysis that follows we attempt to account for its effects.

The metrics shown in Figs. 3 and 4 give the general outline of the model mean flow and response to wind stress forcing changes. We now look to investigate this problem more deeply, focusing on the overturning

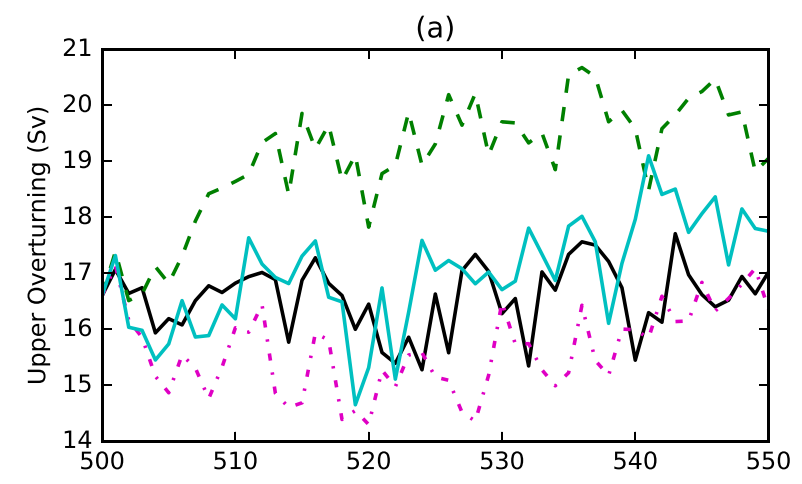

(b)

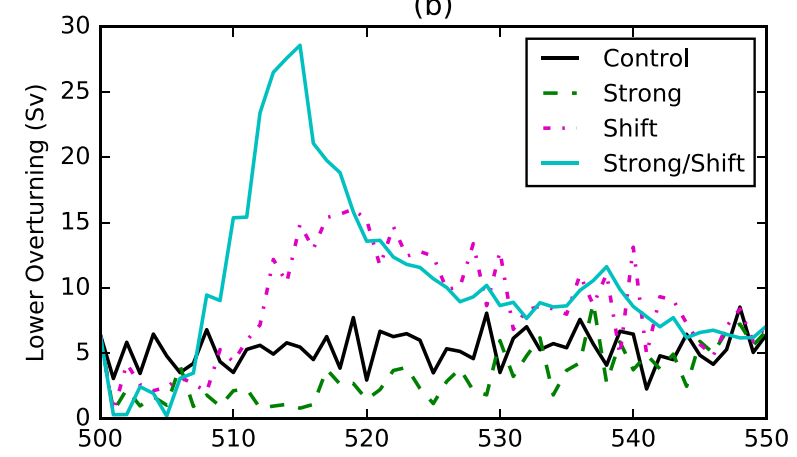

(c)

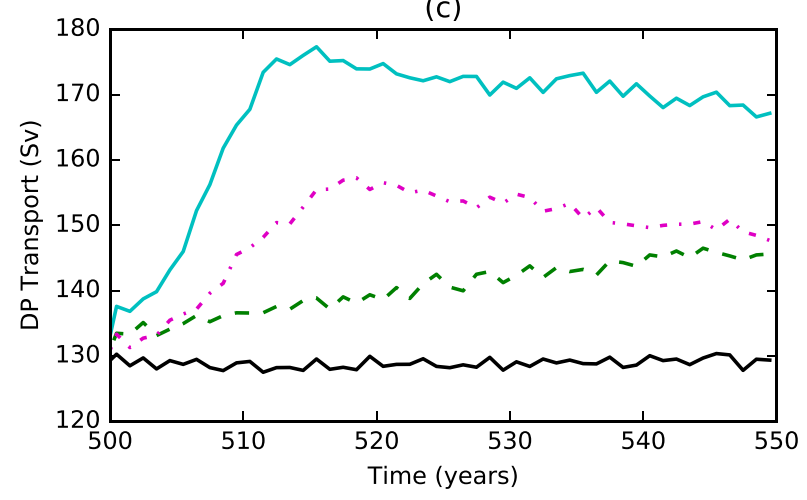

FIG. 4. Time series of annually averaged: (a) upper MOC strength, measured at $26^{\circ} \mathrm{N}$; (b) lower MOC strength, measured at $55^{\circ} \mathrm{S}$; and (c) Drake Passage transport.

circulation changes and the energy budget of the perturbed experiments. We then test the extent to which the overturning and energetic responses can be connected using a depth-density streamfunction.

\section{a. Global energy budgets}

The energetic response to changes in surface forcing can be characterized using the integrated quantities derived in the appendix. The energy reservoirs, sinks, and sources are close to an equilibrium state for the control simulations, as indicated by the black lines in Fig. 6, and the net APE budget is approximately closed. Note that deep-ocean temperature drifts in this model even after a 500-yr spinup, meaning that the BPE is not 

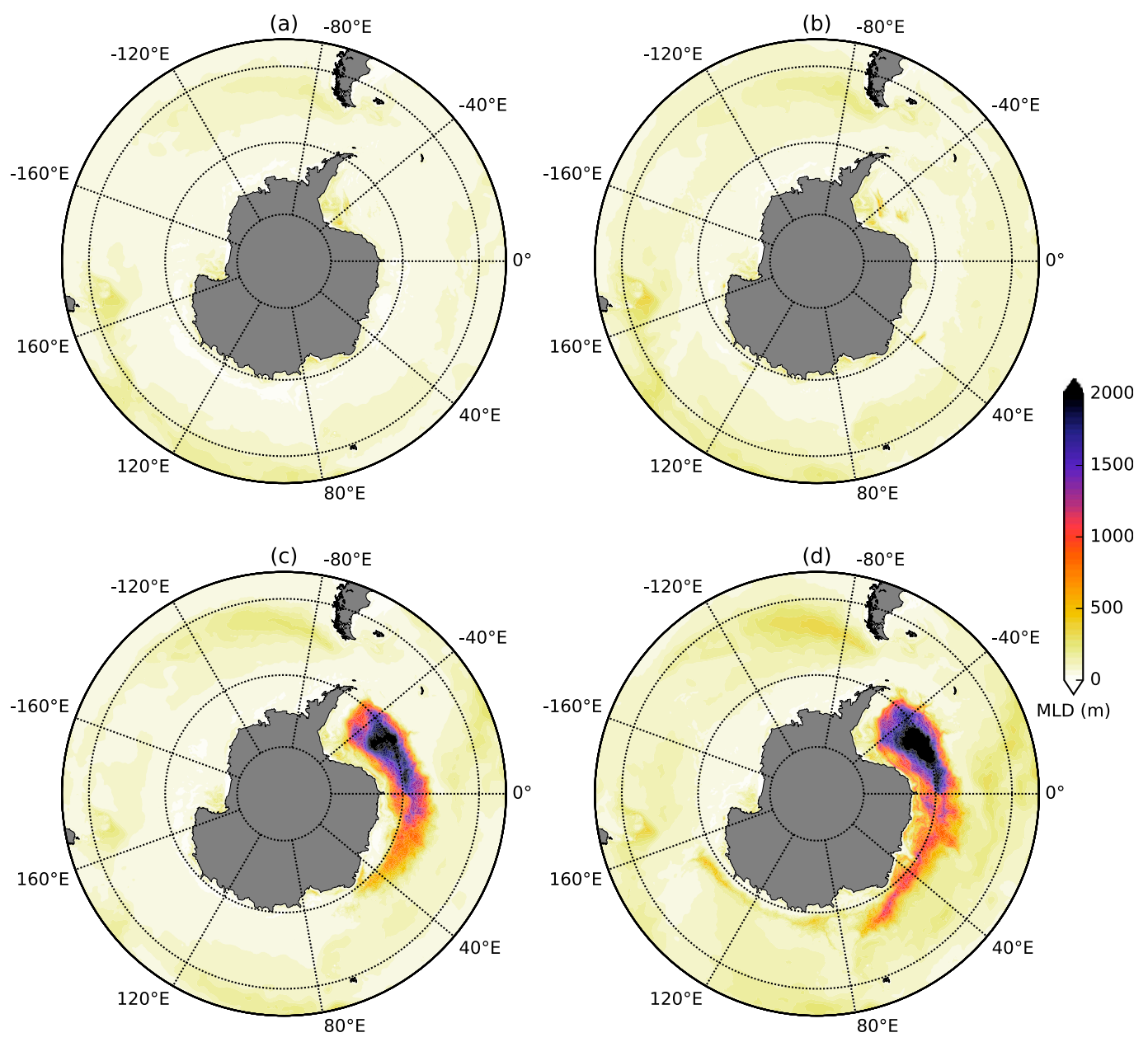

FIG. 5. Southern Ocean mixed layer depth averaged from year 510-520 for (a) control, (b) strong, (c) shift, and (d) strong/shift.

steady. However, given that BPE plays no active role in the energy cycle, it is omitted from this analysis. The APE reservoir is approximately $10^{4}$ times larger than $\mathrm{KE}$ in the control case, but there is no evidence that the size of the energy reservoir is dynamically important; instead it is the flux of energy between reservoirs that is of most relevance to the circulation (Hughes et al. 2009).

When Southern Ocean winds are strengthened, there is an increase in both KE and APE (green dashed lines in Figs. 6a,b). This increase is due to the large jump in wind stress power input at year 500 (Fig. 6c), while input from surface buoyancy flux is not significantly different from the control case (Fig. 6d). The large increase in wind power input is primarily balanced by dissipation (not explicitly calculated) along with a small increase in the rate of conversion from KE to APE (Fig. 6e; noting that the net KE-APE conversion term is negative in this model but is less negative under strengthened winds). Thus, most of the additional mechanical energy from the anomalous winds is stored in the APE field (the increase in APE being 100 times greater than the increase in KE). Both diffusive and convective power contributions increase in magnitude, which also provides a net APE contribution (Figs. 6f,g). Here, the convective adjustment scheme is dominated by near-surface Southern Ocean changes, from which we infer that Southern Ocean upwelling is partly balanced by enhanced convection. Figure $6 \mathrm{~h}$ shows that the APE is close to equilibrium in the reference case and highlights the total change in each of the perturbed cases.

The shift case also enhances both KE and APE (at least over the first $30 \mathrm{yr}$; dashed-dotted magenta lines in Figs. 6a,b) despite the reduction of wind power input due to the geometric effect of a poleward shift in winds (Fig. 6c). This wind power decrease is counteracted by polynya activity in the Weddell Sea, which is associated with strong buoyancy loss and hence APE generation from surface buoyancy flux (Fig. 6d). Consequent 
(a)
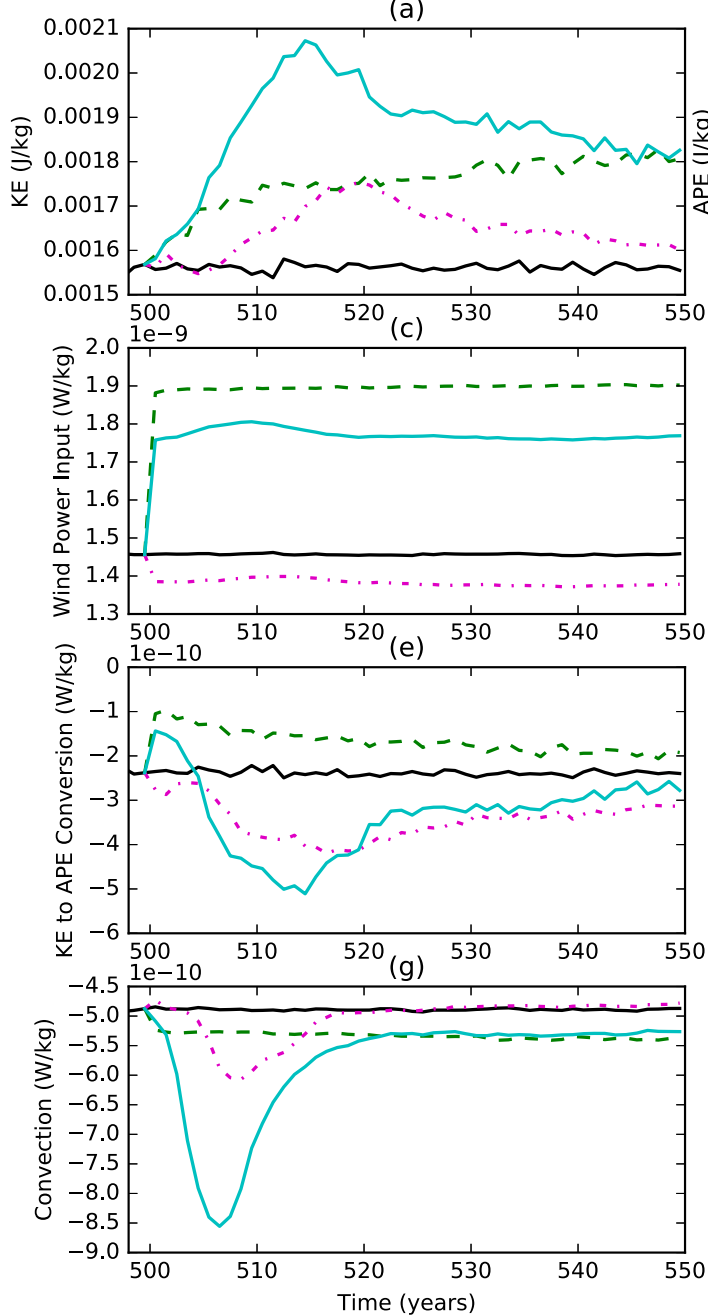

(b)
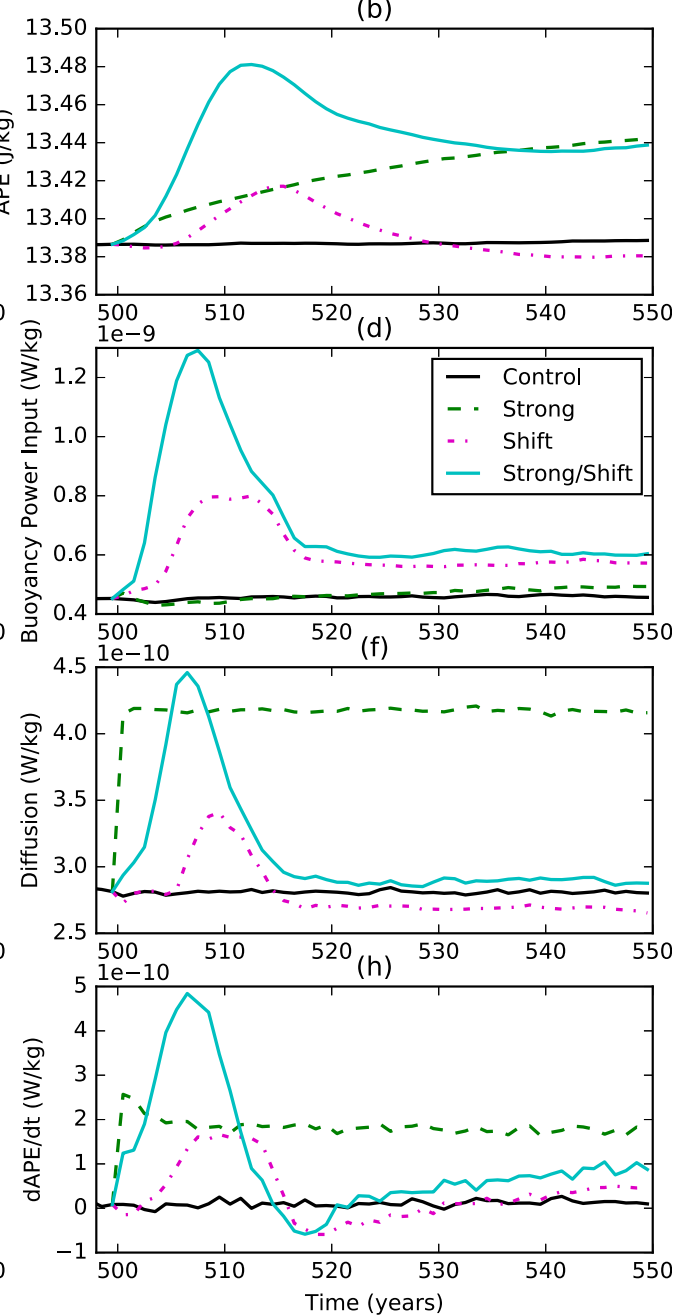

FIG. 6. Annually and globally averaged energy and power diagnostics for the four different simulations: (a) KE, (b) APE, (c) power input to KE from wind stress, (d) power input to APE from surface buoyancy forcing, (e) rate of energy conversion from KE to APE (negative indicating a net source of KE), (f) rate of energy input from diffusive processes (a positive source of APE), (g) loss of APE to convective adjustment, and (h) the sum of (d)-(g), which gives the total rate of change of APE, indicating the extent to which the energy calculations are balanced. The ocean weighs approximately $1.4 \times 10^{21} \mathrm{~kg}$ (Gill 1982), so that $10^{-9} \mathrm{~W} \mathrm{~kg}^{-1}$ is equivalent to $1.4 \mathrm{TW}$.

sinking of dense water enhances the rate of APE to KE conversion (negative values in Fig. 6e), thereby strengthening the lower MOC (Fig. 4b). There is also direct loss of APE through convective adjustment (Fig. 6g) with a small diffusive contribution. Toward the end of the 50-yr simulation the effects of the polynya diminish and APE is reduced beneath the level of the control simulation.

When both the strengthening and shifting of winds are applied, elements of both individual perturbations can be detected, but they cannot be linearly superimposed (solid cyan lines in Fig. 6). The polynya is much larger in extent, resulting in greater surface buoyancy forcing (Fig. 6d), larger KE and APE peaks (Figs. 6a,b) and stronger convection (Fig. 6g). The APE to KE conversion initially weakens (because of the stronger wind input to KE; Fig. 6c) but then is overwhelmed by dense water sinking from the polynya region (negative values in Fig. 6e). Thus, the global energy balance, by integrating over numerous processes, does not provide a clear breakdown of the individual components of the energy budget. For this reason, we look to local energy diagnostics to understand how energy propagates through the ocean model.

\section{b. APE density}

The dynamical implications of changes in the energy budget can be characterized by regional variations in 


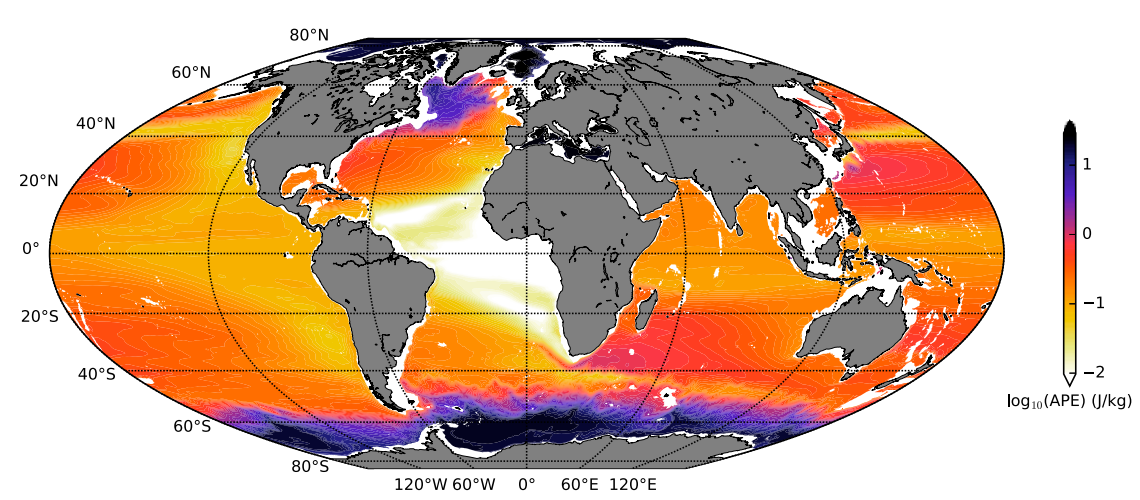

FIG. 7. The logarithm of APE density averaged between 100 and $1500 \mathrm{~m}$, over the course of the control simulation.

energy, focusing primarily on APE density, as outlined in section 2c. The mean value of APE density (averaged over depths of $100-1500 \mathrm{~m}$ ) is shown in Fig. 7 for the 50 -yr average of the control case. Noting the logarithmic color scale, this figure shows that the dominant storage of APE occurs at high latitudes, where dense water can be found close to the surface; this water contains energy that is available to be converted to kinetic energy by sinking through the depth of the ocean to its reference level. At equatorial latitudes, APE density is two orders of magnitude smaller but still nonzero in regions where fluid is lighter than the reference state. APE density is small in the North Pacific Ocean, but large in the North Atlantic Ocean, and has a strong gradient across the subpolar gyre boundary in the North Atlantic Ocean (and across the ACC in the Southern Ocean). In some marginal seas (e.g., the Mediterranean Sea) dense water piled up behind the sill has APE, which cannot be released; Stewart et al. (2014) propose a method to deal with this issue but we have not applied their solution here.

In each of the wind perturbation simulations shown in Fig. 6, there is an overall APE increase, which is largest in years 505-515. The APE density highlights variations in the pattern of APE change between the three cases. The change in APE in the upper ocean $\triangle \mathrm{APE}$ for years 505-515 is shown in Fig. 8. The strong winds (Fig. 8a) increase APE over most regions of the Southern Ocean, particularly at the central latitudes $\left(\sim 55^{\circ} \mathrm{S}\right.$; see green dashed line in Fig. 8d). In contrast, the shift case is dominated by a dipole pattern with a decrease in APE density on the northern flank of the ACC (especially in the Atlantic and Indian Ocean sectors) and increased APE south of $62^{\circ} \mathrm{S}$ (Fig. 8b; dashed magenta line in Fig. 8d). This dipole pattern is partly due to the southward shift in the location of Ekman transport, but a strong component of the APE increase south of the ACC is due to the polynya opening in the Weddell Sea.
In addition, the ribbon of enhanced APE around the Antarctic coastline is likely related to the wind-induced shoaling of the Antarctic Slope Front documented previously using this ocean model (Spence et al. 2014) and may directly modify ACC transport (Langlais et al. 2015). In the strong/shift case the enhanced wind stress moderates the APE decrease at $60^{\circ} \mathrm{S}$, reducing the dipolelike nature of the response (Fig. 8c). The result is that the APE increase (especially in the Weddell Polynya region) dominates the response, leaving only a small region east of the Weddell Sea where $\triangle \mathrm{APE}$ is negative and only a small range of latitudes over which APE decreases in the zonal average (cyan line in Fig. 8d).

The APE density analysis reveals that the local response to Southern Ocean wind perturbations is composed of an Ekman response (monopole for strong and dipole for shift, where wind forcing is reduced on the northern flank and decreases on the southern flank), the polynya response, and the Antarctic shelf dynamics. It is the Ekman response, most obvious in the strong case, that we are most concerned with here because of its potential impact on the upper MOC. As such, one surprising aspect of the global changes in APE density is that, for the strong case, there is a systematic growth in APE density in the North Atlantic Ocean. This change is focused on the Greenland-Iceland-Norway (GIN) Seas (Fig. 9a) where we see a systematic increase in APE density by the last decade of the 50-yr simulation (associated with a cooling of $2^{\circ}-4^{\circ} \mathrm{C}$ and a slight freshening, resulting in a maximum total density difference of less than $0.5 \mathrm{~kg} \mathrm{~m}^{-3}$ ). A time series of APE density averaged of the GIN seas shows that only the strong case exhibits this systematic positive APE trend (Fig. 9b). The strong case is also the only one with a clear positive trend in the $26^{\circ} \mathrm{N}$ upper MOC (Fig. 4a). We infer from this result that one possible mechanism for enhancement of the upper overturning cell in the presence of stronger Southern 

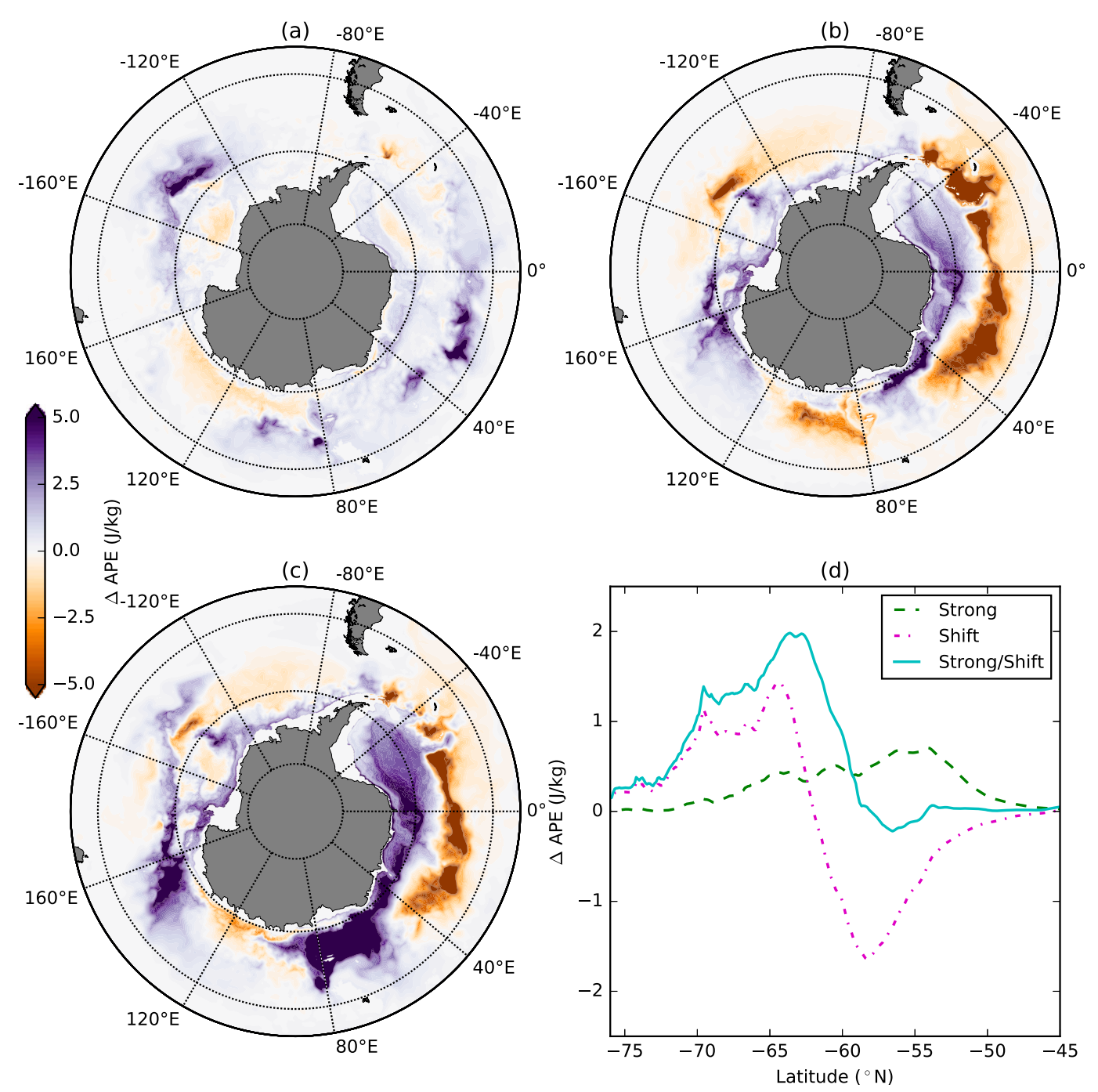

FIG. 8. The change in Southern Ocean APE density from the control mean state (shown in Fig. 7) and the model state averaged over years 505-515 and depths 100-1500 m of the perturbation simulations: (a) strong case, (b) shift, (c) strong/shift, and (d) the zonal average.

Ocean winds is feedback with the production of dense water in the GIN seas. Thus, the enhanced northward buoyancy transport implied by an increase in the upper overturning cell and the simulated growth of APE in the North Atlantic Ocean may act to reinforce each other.

\section{c. Overturning circulation}

The response of the global overturning circulation to changes in Southern Ocean wind stress is now analyzed using two different metrics: the standard latitudedensity overturning circulation $\Psi_{y \rho}$ [i.e., calculated on density surfaces and plotted in latitude-density space as per Eq. (16)] and the overturning circulation calculated in depth-density space $\Psi_{z \rho}$ [Eq. (17)]. As highlighted in section $2 \mathrm{~d}$, the latter streamfunction has the advantage that it is directly related to the resolved conversion between APE and KE $\Phi_{z}$ and thus provides a bridge between the energy analysis conducted above and the circulation (Nycander et al. 2007).

We begin with the latitude-density streamfunction in Fig. 10. We plot the decadal average of the overturning anomaly from the 50-yr control average at years 515-525 (where the Weddell Polynya remains active in the shift cases and the lower cell is maximal) and years 540-550 (the last decade of the simulation and hence the closest to equilibrium). The strong case shows an intensification of the upper MOC, which is most apparent in the Southern Hemisphere by years 515-525 (the green patch in Fig. 10a) but also influences the Northern Hemisphere (green shading in Figs. 10a,d). The interhemispheric 
(a)

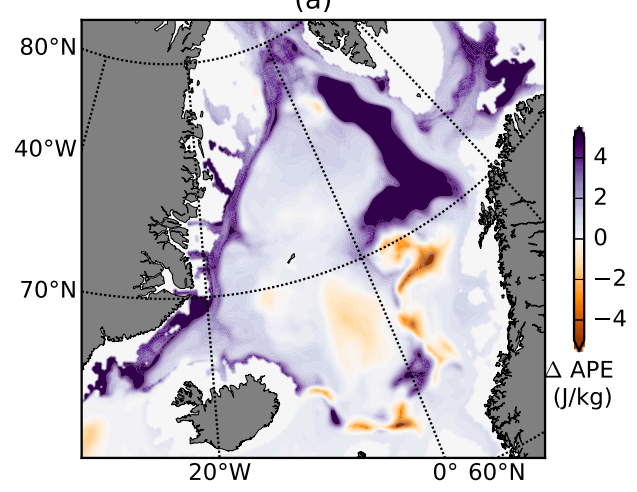

(b)

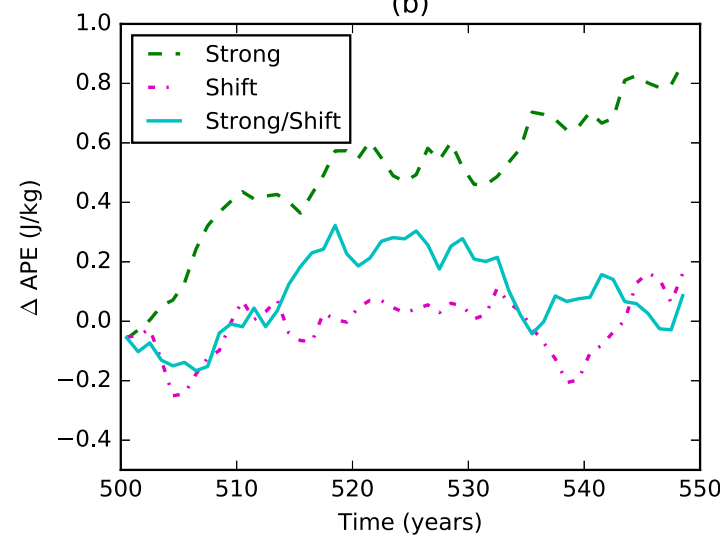

FIG. 9. (a) Change in APE density in the Greenland-Iceland-Norway Seas for the strong case for years 540-550, averaged over depths of 200-300 m. (b) The area-averaged change in APE in this region from each perturbation case over the course of the $50-\mathrm{yr}$ simulation.

overturning (i.e., the magnitude of the overturning cell measured at the equator; not shown) is amplified by about $4 \mathrm{~Sv}$ by the end of the 50 -yr simulation.

The latitude-density overturning circulation in the shift case is dramatically different from the strong case. By years 515-525 the shift case shows an intensification of the lower cell due to the Weddell Sea Polynya (Fig. 4b and intense purple spot at $60^{\circ} \mathrm{S}$ and density $1037 \mathrm{~kg} \mathrm{~m}^{-3}$ in Fig. 10b) as well as a weakening of the southern branch of the upper MOC. This weakening of the upper cell is most obvious at $40^{\circ} \mathrm{S}$ and is likely dominated by transient adjustment of the water masses, as by years 540-550 the southern branch of the upper MOC has returned toward the control case (Fig. 10e). The only significant interhemispheric effect is a small patch of green in the northern latitudes, indicating that the
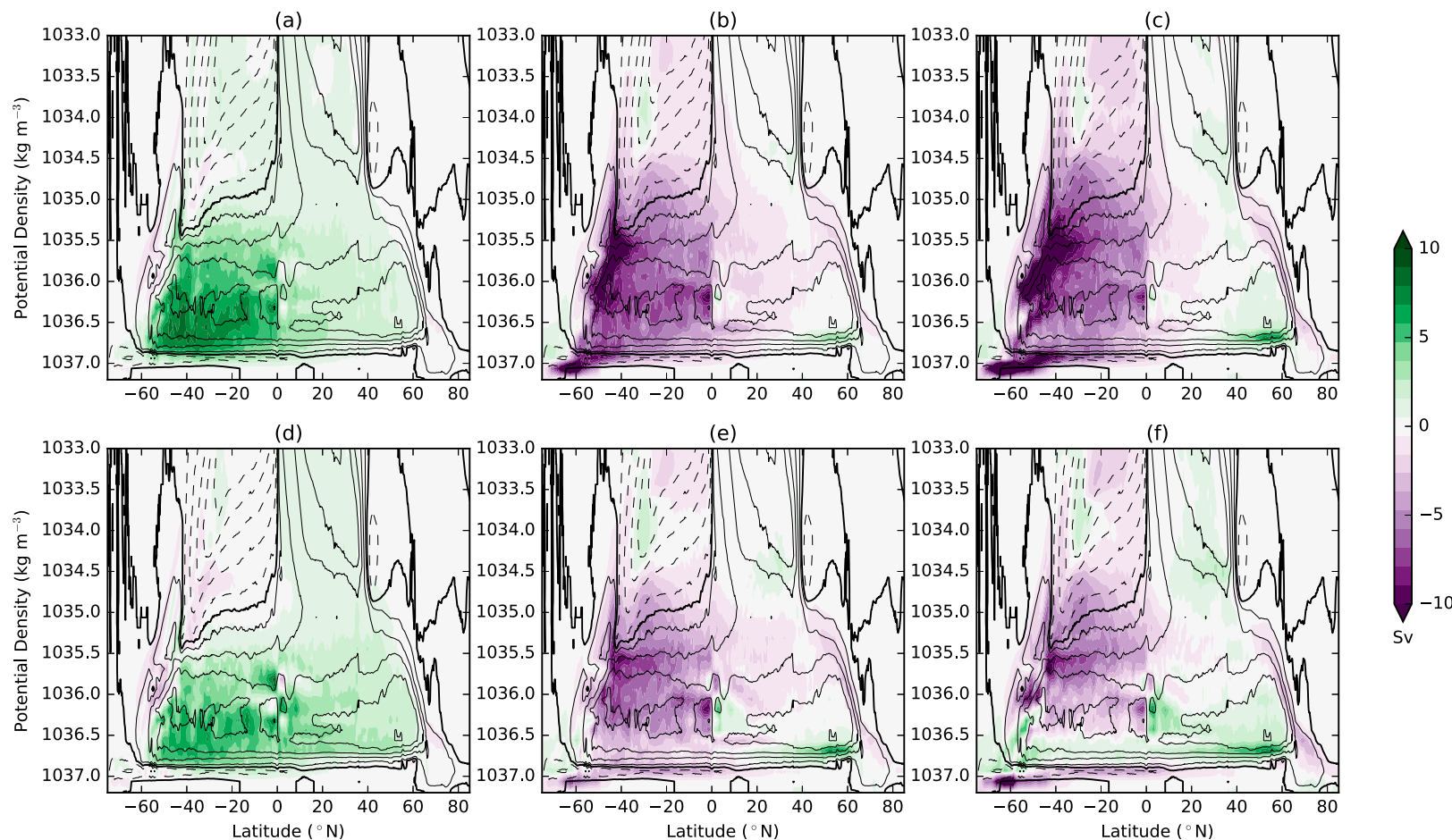

FIG. 10. Difference between the decadal-mean latitude-density streamfunction and the 50 -yr mean control latitude-density streamfunction: (a) strong, years 515-525; (b) shift, years 515-525; (c) strong/shift, years 515-525; (d) strong, years 540-550; (e) shift years 540550; and (f) strong/shift years 540-550. In each panel, black contours show the 50-yr mean control streamfunction, with a contour interval of $4 \mathrm{~Sv}$; dashed contours are negative and the heavy contour is zero. 
northern branch of the upper MOC has expanded to incorporate denser water masses without altering the total meridional transport. We therefore regard the northern branch of the upper cell as being relatively insensitive to the wind shift perturbation (Fig. 4a) and note that the interhemispheric overturning circulation is weaker than the control by $2-3 \mathrm{~Sv}$. The strong/shift case is primarily a linear superposition of the two above cases. Initially, there is a strong increase in the lower MOC and a decrease in the southern branch of the upper MOC (Fig. 10c), but over time there is a slight amplification of the upper MOC in both hemispheres (Fig. 10f).

The ocean overturning circulation is characterized by downwelling of dense water, balanced by upwelling of lighter water and therefore is intrinsically connected with the conversion between APE and KE [Eq. (4)]. However, this conversion of energy is represented in Fig. 6e by a single number at any given time and thus cannot inform where or how changes in circulation occur. Expanding this single number into the associated depth-density overturning [Eq. (17)] is more informative; it shows that the net advective KE-APE conversion may consist of several opposite overturning cells (as shown in Fig. 11 for the 50-yr control case). The depth-density streamfunction therefore monitors the densities and depths at which APE to KE conversion $\Phi_{z}$ is occurring, as demonstrated by the global 50-yr control depth-density overturning streamfunction (Fig. 11a). The magenta colors indicate the weak lower MOC in this model, while the green cell is the upper MOC. The upper MOC in this framework is thermally indirect, meaning that upwelling water is denser than downwelling water (Nycander et al. 2007). Note that the streamfunction is only shown over the range of potential densities exceeding $1034.5 \mathrm{~kg} \mathrm{~m}^{-3}$ and thus omits a strong, thermally direct, near-surface subtropical cell.

In this model the strength of the depth-density streamfunction in the region where Southern Ocean upwelling occurs (depths of 500 to $1500 \mathrm{~m}$ ) is weak; Fig. 11b shows that this effect is due to cancellation between the thermally indirect Southern Hemisphere branch and a thermally direct Northern Hemisphere branch of the circulation. Here, the depth-density streamfunction is divided into the Southern Hemisphere overturning, shown on the left, and the Northern Hemisphere on the right, with the sign of the streamfunction inverted and the $x$ axis (potential density) reversed in direction so that density is greatest at both ends of the figure (mimicking the position of polar dense water formation). The actual water mass transformation is concentrated in a small wedge matching the ranges of depth and density that are shaded in magenta/green in Fig. 11a: the top left in the Southern Hemisphere and the
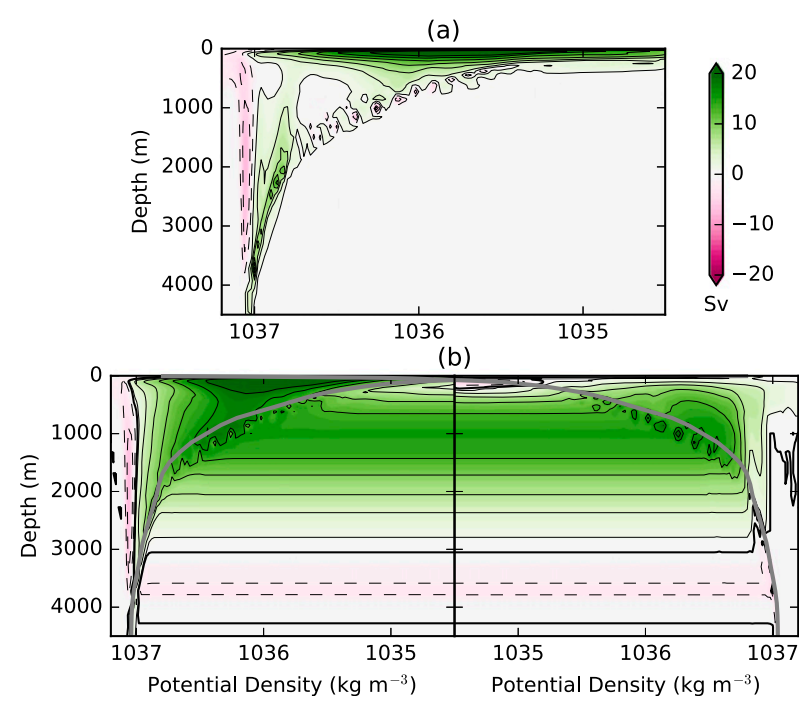

FIG. 11. (a) Depth-density streamfunction for the 50-yr control case (waters denser than $1034.5 \mathrm{~kg} \mathrm{~m}^{-3}$ ) and (b) the depth-density streamfunction calculated independently for the (left) Southern Hemisphere and the (right) Northern Hemisphere. The $x$ axis (potential density) is reversed between the two hemispheres. Gray lines show the maximum potential density at the equator as a function of depth. Water mass transformation is concentrated in a small wedge matching the ranges of depth and density that are shaded in magenta/green in (a); thus, streamlines located beneath the gray lines in (b) do not indicate the presence of circulation at those depths and densities.

top right in the Northern Hemisphere. However, in each hemisphere, the estimated streamfunction does not close at the lower edge of each wedge, indicating the water masses that are transported between the hemispheres. The hemispheric streamfunctions thus match at the centerline of the plot, yielding the net interhemispheric exchange for each depth class. The correspondence between the net interhemispheric overturning in this analysis and the latitude-depth streamfunction at the equator is exact; furthermore, along the gray line (representing maximum equatorial density) the overturning matches the latitude-density streamfunction.

There is a relationship between the depth-density streamfunction and the latitude-density overturning streamfunction. On the left-hand side of Fig. 11b there is a negative circulation cell; this is a vertical downward flux of very dense water, which returns to the surface at slightly lower density. It is thus thermally direct in the sense that it involves a net conversion of APE to KE. It is connected to a weak abyssal overturning cell, which extends into the Northern Hemisphere, but this water mass does not reach the surface there. We therefore consider it to be a close analogy to the lower MOC in latitude-depth overturning space. 
The cell shown in green is analogous to the upper MOC. It is thermally indirect in the Southern Hemisphere, indicating that closed contours in this hemisphere (which extended down to about $1400 \mathrm{~m}$ in the central latitudes of the Southern Ocean) require a net input of mechanical energy from surface wind stress. However, this upwelling is connected to the northern branch of the upper overturning cell, which is thermally direct (recalling that the sign of the streamfunction is reversed in the Northern Hemisphere). Thus, the following scenario can be constructed. Dense water, which sinks in the North Atlantic Ocean, crosses the equator (marked by the gray lines in depth-density space) and is then absorbed into the Southern Hemisphere streamfunction. It then reaches the surface along isopycnals (actually becoming slightly less dense closer to the surface) and transformed to lighter water classes before being subducted back into the interior. When the Northern and Southern Hemisphere streamfunctions are superimposed (Fig. 11a), the net result is that circulation is dominated by a near-surface, wind-driven cell, with a deep recirculation (perhaps involving cabbeling/ thermobaric energy conversions at depth in the Southern Ocean; Urakawa et al. 2013) that does not reach the surface and a thermally direct abyssal cell. This diagnostic implies that the net interhemispheric overturning at equilibrium in this model is neither thermally direct nor indirect; it is primarily adiabatic, as suggested by Wolfe and Cessi (2011).

In the strong winds case (Fig. 12a) the thermally indirect cell in the Southern Hemisphere is intensified, and some of this intensification propagates into the Northern Hemisphere. In the northern regions there is thus a stronger thermally direct circulation, which intensifies gradually over the 50-yr simulation. The shift case (Fig. 12b) has a stronger thermally direct cell in the Southern Hemisphere and a weaker interhemispheric circulation. There is just a small shift in the density at which deep water is formed in the Northern Hemisphere (a faint green patch at potential density $1036.7 \mathrm{~kg} \mathrm{~m}^{-3}$, but no net intensification of the circulation). The disconnect between the interhemispheric exchange and the northern cell implies that this simulation is still adjusting to the change in forcing. The strong/shift case possesses elements of the other two cases (Fig. 12c), with a stronger lower cell and weaker interhemispheric overturning, although Southern Ocean upwelling has intensified.

The depth-density streamfunction can also be divided into mean and eddy components, as shown in Fig. 13 for the Southern Hemisphere only. Here, we see that the increase in the wind-driven mean overturning cell is largest in strong case (Fig. 13b) but also significant in the strong/shift simulation (Fig. 13h). In both cases, this

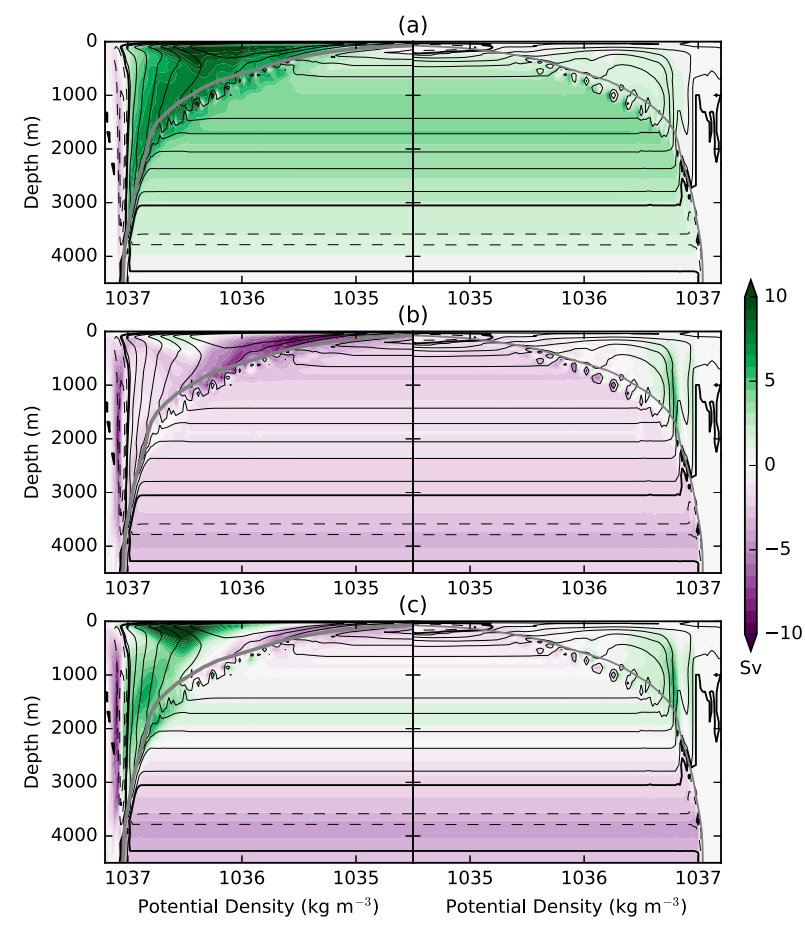

FIG. 12. The depth-density streamfunction anomaly from the control for the final decade (years 540-550) for (a) strong, (b) shift, and (c) strong/shift, separated into (left) Southern Hemisphere and (right) Northern Hemisphere contributions. The $x$ axis (potential density) is reversed between the two hemispheres. Gray lines show the maximum potential density at the equator as a function of depth. Black contours show the 50-yr mean control streamfunction, with a contour interval of $4 \mathrm{~Sv}$; dashed contours are negative and the heavy contour is zero.

intensification of the mean circulation is counteracted by an increase in the eddy overturning (Figs. 13c,i), meaning that this flow is partially eddy compensated. It is notable that this eddy compensation occurs entirely within the Southern Hemisphere, while the interhemispheric component of the overturning is a mean flow feature (indicated by the closure of the Southern Hemisphere eddy streamfunction). However, the eddying component of the overturning accounts entirely for the changes in the lower MOC, which is largest in the shift and strong/shift cases (Figs. 13f,i). This cell should be interpreted not as the response of mesoscale eddies but instead as the result of transient flow such as plumes and overflows, which compose the downwelling branch of the abyssal cell.

\section{Discussion and conclusions}

The response of the global overturning circulation to changes in Southern Ocean westerly winds is complicated by factors such as mesoscale eddies, polynya formation, and the interhemispheric nature of the 
(a)

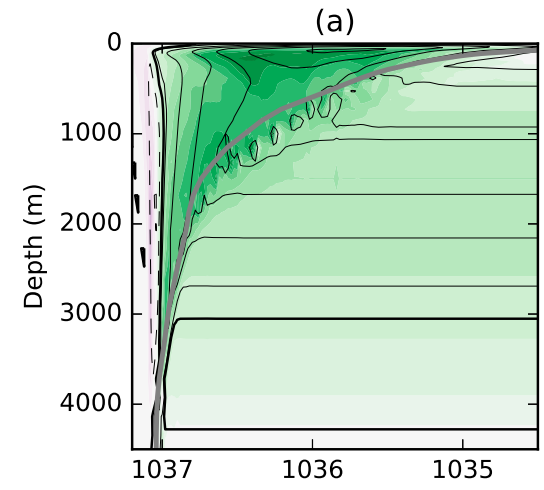

(d)

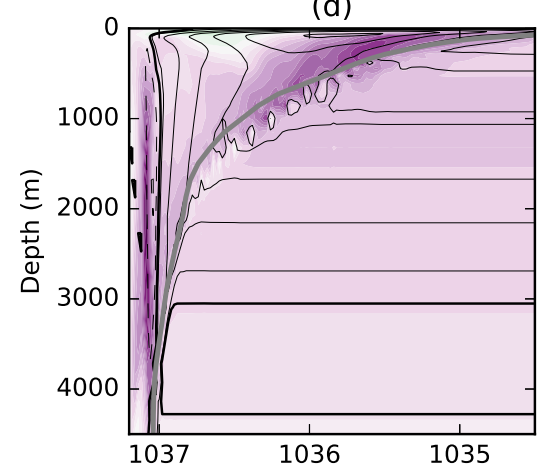

(g)

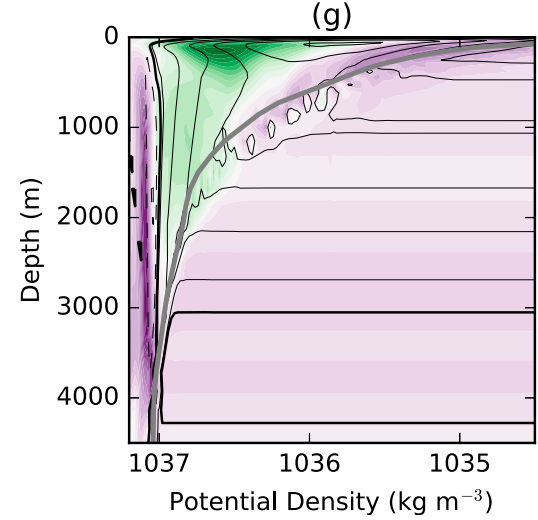

(b)

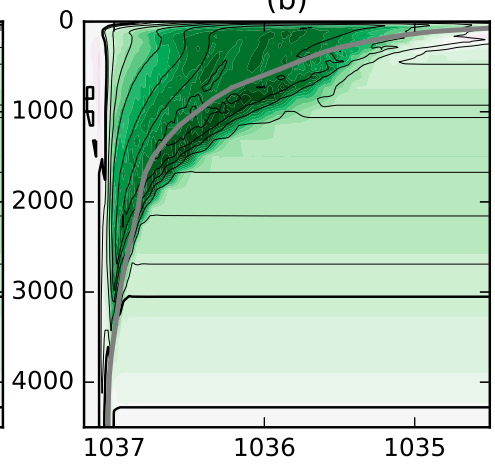

(e)

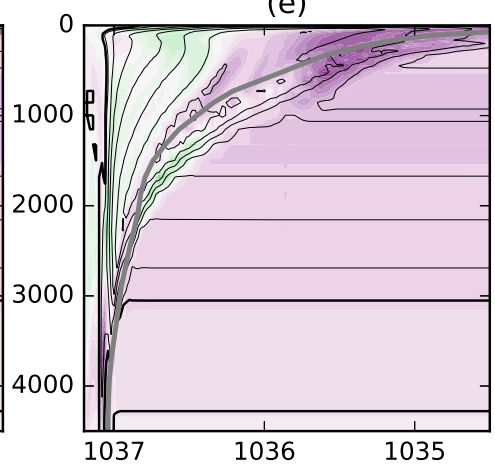

(h)

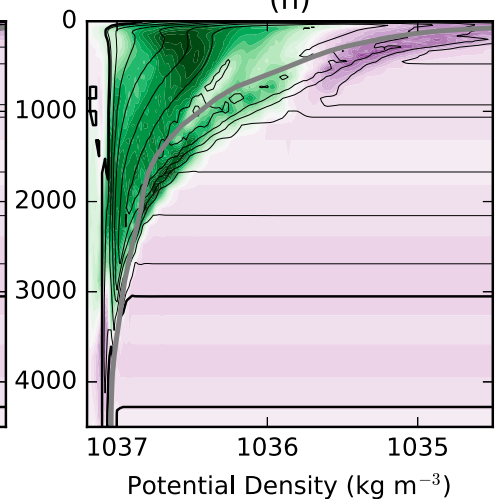

(c)

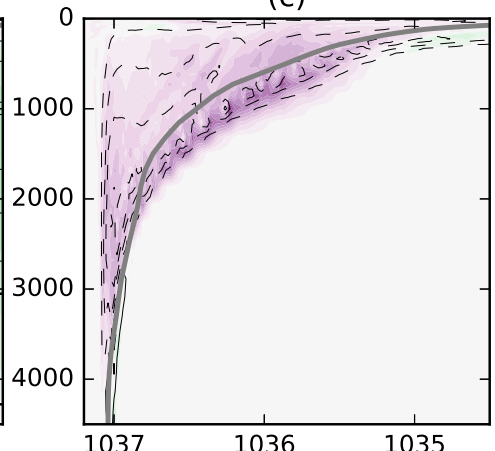

(f)

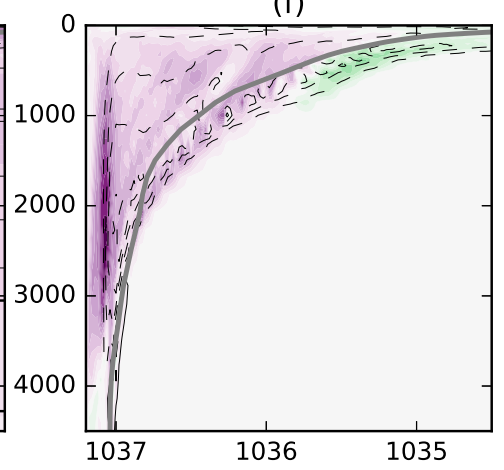

(i)

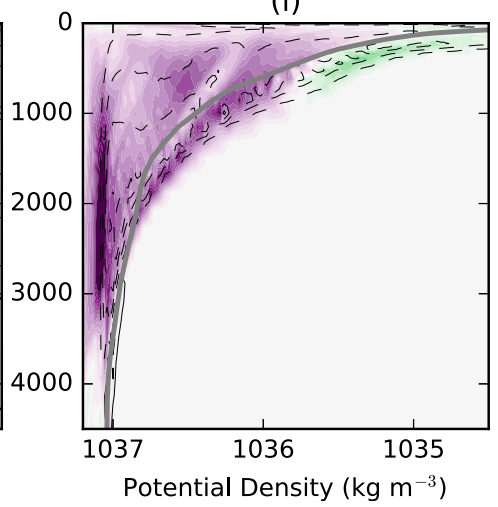

15

10

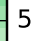

$-0$

$-5$

$-10$

FIG. 13. Southern Hemisphere depth-density streamfunction anomalies averaged over years 520-530 for (a)-(c) strong, (d)-(f) shift, and (g)-(i) strong/shift simulations. (left) The total streamfunction, which can be divided into a (center) mean contribution and the (right) eddy contribution. Black contours show the 50-yr-averaged streamfunctions from the control case (contour interval $4.5 \mathrm{~Sv}$ ). Gray lines show the maximum potential density at the equator as a function of depth.

overturning circulation. In this study, our goal was to reconcile these complicated responses using a combination of energetic and overturning analyses. These two approaches intersect at the depth-density streamfunction, separated into its hemispheric components, which represents the resolved conversion of energy between kinetic energy (KE) and available potential energy (APE) reservoirs.

When we impose a strengthening of Southern Ocean westerly winds (the strong case) on the control simulation, there is a strong additional input of KE into the Southern Ocean, a fraction of which is transferred to
APE via the upwelling of dense water. Thus, a circumpolar band of increased APE forms in the upper waters of the Southern Ocean. This APE formation is opposed by a small increase in the parameterized convection and an increase in the resolved eddy overturning circulation, both of which act to extract APE. Nonetheless, the net effect of stronger winds is an amplification of the southern branch of the upper MOC, which is apparent in both the depth-density streamfunction and the latitudedensity streamfunction.

A notable feature of the depth-density streamfunction response to enhanced winds is that it does not 
close in the Southern Hemisphere, implying an interhemispheric component to the overturning response. This interhemispheric exchange in the depth-density streamfunction exactly matches the net latitude-depth streamfunction at the equator and builds gradually over the course of the 50-yr strong perturbation. Thus, the signature of enhanced overturning is significant at $26^{\circ} \mathrm{N}$, resulting in an increase of $4 \mathrm{~Sv}(25 \%)$ of the upper MOC in this model. However, the depth-density streamfunction highlights that this North Atlantic response is a thermally direct cell; that is, it represents a conversion of energy from APE to KE. Intriguingly, this enhancement is associated with an increase of APE in the GreenlandIceland-Norway Seas, implying that the enhanced upper MOC is associated with a stronger source of APE in the Northern Hemisphere. While these cumbersome, global, eddy-permitting simulations are difficult tools to use for ascertaining cause and effect, this result plausibly suggests that the mechanisms for enhanced interhemispheric overturning involves the remote influence of Southern Hemisphere winds on the Northern Hemisphere APE budget, achieved perhaps by radiation of internal Kelvin and Rossby waves throughout the Atlantic Ocean. The mechanisms of interhemispheric communication in this model are a topic of continued investigation.

A southward shift of the Southern Ocean westerly winds in this model is associated with a decrease in the total wind power input (due to the geometric effect); yet, both APE and KE are increased by polynya activity in the Weddell Sea enhancing surface buoyancy fluxes south of the Antarctic Circumpolar Current (ACC). The polynya ignites an interhemispheric response in the abyssal cell (Figs. 10b,c) and consequent amplification of the ACC (Howard et al. 2015). But the upper MOC undergoes an apparent transient weakening in the Southern Hemisphere, followed by a gradual recovery. The transient weakening is focused on $40^{\circ} \mathrm{S}$, but it has a modest influence on the northern branch of the upper cell. Given its transient nature, it is possible that the weaker overturning may be induced by a temporary disconnect between the density at which upwelling occurs in the Southern Hemisphere and the density of the southward, thermally direct, branch of the upper cell in the Northern Hemisphere. This hypothesis may explain the slight densification of the upper MOC in the Northern Hemisphere (without a net increase in the volume flux) and may lead to a multicentennial adjustment ending with similar net overturning circulation as the equilibrium control simulation.

The combination of strengthening and shifting of the winds contains elements of both individual components. The Weddell Polynya and lower MOC are further amplified, as well as the surface buoyancy flux. Thus, the net energy conversion anomaly is from APE to KE, meaning that global energy budgets say little about the energetic influence on individual overturning cells. The amplification of this abyssal cell is seen in both the latitude-density and depth-density streamfunctions, but it is a transient effect due to the breakdown of the polynya after year 520 . However, it has also been proposed that the abyssal cell may be sensitive to the strength of abyssal mixing, induced by the wind-driven Southern Ocean mesoscale eddy field (Stanley and Saenko 2014; Broadbridge et al. 2016). This mechanism would act to sustain the thermally direct abyssal cell by enhancing the water mass transformation that is required to close the magenta cell in Fig. 11a; however, under the mixing parameterizations used in this model, the mechanism is absent from the present simulations.

In the early years of the strong/shift simulation, there is an increase in Southern Ocean upwelling, with partial eddy compensation, but the interhemispheric component of the upper MOC is weak and only grows to exceed the control case after $40 \mathrm{yr}$. The inference of this result is that the initial, transient response to intensification of the Southern Ocean wind-driven upwelling is entirely contained within the Southern Hemisphere and that intensification of the global upper cell, if it happens at all, occurs on longer time scales. But, for all practical purposes these results reveal that, on human time scales, the effect of intensified winds on the AMOC may be counteracted (partially or wholly) by a southward shift in the wind field. Since shifting and strengthening of Southern Hemisphere winds seems to happen in concert (e.g., Bracegirdle et al. 2013) the actual AMOC response to Southern Ocean wind changes may be muted.

The overturning sensitivity to Southern Ocean winds is often pitched as a balance between eddy activity and wind-driven upwelling (Gent 2016). The present simulations, however, outline additional influences. The energetics of the resolved flow shows that, despite the influence of eddy compensation, the increased wind stress can intensify the interhemispheric component of the overturning. This interhemispheric intensification requires a stronger, thermally direct Northern Hemisphere overturning, which may be induced by teleconnections between the hemispheres that modify the Northern Hemisphere APE budget. However, the transient nature of the response to wind shifts and the lack of a clear signal in the interhemispheric overturning in the strong/shift case imply that there are many additional complexities. In addition, local parameterized convection can also extract APE in an ocean model; in the real ocean this convective flux occurs due to a net advective transport of buoyancy by the transient flow 
and is directly associated with changes in vertical transport and a conversion of energy from APE to KE. The lack of resolved convection in the ocean models limits the application of energetic arguments to the overturning circulation.

These results imply that the response of the climate system to varying Southern Ocean winds depends intricately on the pattern of wind and surface buoyancy flux changes. We suggest that further work is needed to delineate the extent to which eddies and convection oppose changes in the forcing, to distinguish the transient from the equilibrium response, to clarify the individual Northern and Southern Hemisphere influences, and to determine the extent to which shifting versus intensification of winds modify the circulation. This study has made preliminary steps in these directions, especially in connecting the energetic response with the circulation changes, but studies with higher-resolution, more realistic forcing and with a range of climate models and scenarios are required before we can confidently constrain the climate system and carbon cycle response to Southern Ocean wind stress changes.

Acknowledgments. Our thanks to Jan Zika, who suggested the hemispheric decomposition of the depthdensity streamfunction used in Figs. 11 and 12, and to Neil Swart, who commented on the first draft of the paper. This research was undertaken on the NCI National Facility in Canberra, Australia, which is supported by the Australian Commonwealth Government. AMH was supported by an Australian Research Council Future Fellowship FT120100842 and PS was supported by an Australian Research Council DECRA Fellowship DE150100223. SMD was supported by the Australian Government's Business Cooperative Research Centres Programme through the Antarctic Climate and Ecosystems Cooperative Research Centre (ACE CRC).

\section{APPENDIX}

\section{Derivation of Model APE Diagnostics}

We assume that density $\rho$ is well represented by the potential density referenced to $2000 \mathrm{dbar}$ [Saenz et al. (2015) show that this is a consistent approximation to using the full nonlinear equation of state]. We can then write the density tendency equation as follows:

$$
\rho_{t}+\mathbf{u} \cdot \nabla \rho=\left[\rho_{t}\right]_{d}+\left[\rho_{t}\right]_{c}-Q_{\rho},
$$

where $\mathbf{u}=(u, v, w)$ is the velocity vector, $\left[\rho_{t}\right]_{d}$ is the rate of change of density from diffusive processes [background diffusivity, the KPP mixed layer scheme (excluding convection), frazil formation, and the submesoscale parameterization $],\left[\rho_{t}\right]_{c}$ isolates the convective part of the KPP parameterization, and $Q_{\rho}$ is the surface buoyancy forcing (defined so that positive fluxes decrease the density of the surface ocean).

To calculate a potential energy tendency of the model, we take the temporal derivative of Eq. (5) and combine with Eq. (A1) to write

$$
\frac{d E_{p}}{d t}=\frac{g}{\rho_{0} V} \int_{V}-z \nabla \cdot(\mathbf{u} \rho)+z\left[\rho_{t}\right]_{d}+z\left[\rho_{t}\right]_{c}-z Q_{\rho} d V .
$$

From this point, we follow Dijkstra et al. (2014) in explicitly calculating the terms as written using online model diagnostics, rather than the analytical forms of these terms (Winters et al. 1995), which are numerically hard to calculate. The advective terms integrate to zero because of no flux boundaries, with the exception of the vertical term, which is integrated by parts to give a vertical buoyancy flux term, while the surface buoyancy flux term is only nonzero in the upper-ocean grid box, giving

$$
\begin{aligned}
\frac{d E_{p}}{d t}= & \frac{g}{\rho_{0} V} \int_{V} w \rho d V+\frac{g}{\rho_{0} V} \int_{V} z\left[\rho_{t}\right]_{d} d V \\
& +\frac{g}{\rho_{0} V} \int_{V} z\left[\rho_{t}\right]_{c} d V-\frac{g}{\rho_{0} V} \int_{S} \delta_{z}^{1} z^{1} Q_{\rho} d S,
\end{aligned}
$$

where $\delta_{z}^{1}$ is the depth of the upper grid box, $z^{1}$ is its height, and $S$ is the ocean surface. We can write this equation in shorthand as

$$
\frac{d E_{p}}{d t}=\Phi_{z}+\Phi_{d 1}+\Phi_{c 1}+\Phi_{b 1}
$$

Note that if $\delta_{z}^{1}$ and $z^{1}$ are constant, then $\Phi_{b 1}=0$ whenever net surface buoyancy forcing is balanced (i.e., $\left.\int_{S} Q_{\rho} d s=0\right)$.

We can write an analogous equation for the background potential energy:

$$
\frac{d E_{b}}{d t}=\frac{g}{\rho_{0} V} \int_{V}-z_{*} \nabla \cdot(\mathbf{u} \rho)+z_{*}\left[\rho_{t}\right]_{d}+z_{*}\left[\rho_{t}\right]_{c}-z_{*} Q_{\rho} d V .
$$

Following Winters et al. (1995), the advective contributions are zero in a closed domain, leaving

$$
\begin{aligned}
\frac{d E_{b}}{d t}= & \frac{g}{\rho_{0} V} \int_{V} z_{*}\left[\rho_{t}\right]_{d} d V+\frac{g}{\rho_{0} V} \int_{V} z_{*}\left[\rho_{t}\right]_{c} d V \\
& -\frac{g}{\rho_{0} V} \int_{S} \delta_{z}^{1} z_{*}^{1} Q_{\rho} d S
\end{aligned}
$$


or, in shorthand,

$$
\frac{d E_{b}}{d t}=\Phi_{d 2}+\Phi_{c 2}+\Phi_{b 2}
$$

Here, $\Phi_{d 2}$ is the change of APE through irreversible mixing, which is converted to BPE, while $\Phi_{c 2}$ is the analogous pathway for convection, which we expect to be negligible, and $\Phi_{b 2}$ is the conversion of BPE to APE through surface buoyancy flux.

We can then calculate the available potential energy budget as the difference between potential and background potential energy $\left(E_{a}=E_{p}-E_{b}\right)$ :

$$
\frac{d E_{a}}{d t}=\Phi_{z}+\Phi_{d}+\Phi_{c}+\Phi_{b}
$$

where

$$
\Phi_{d} \equiv \Phi_{d 1}-\Phi_{d 2}=\frac{g}{\rho_{0} V} \int_{V}\left(z-z_{*}\right)\left[\rho_{t}\right]_{d} d V
$$

is the net diffusive change in APE,

$$
\Phi_{c} \equiv \Phi_{c 1}-\Phi_{c 2}=\frac{g}{\rho_{0} V} \int_{V}\left(z-z_{*}\right)\left[\rho_{t}\right]_{c} d V
$$

is the net change in APE through the convective component of KPP (expected to be a sink of APE), and

$\Phi_{b} \equiv \Phi_{b 1}-\Phi_{b 2}=\frac{-g}{\rho_{0} V} \int_{S} \delta_{z}^{1}\left(z^{1}-z_{*}^{1}\right) Q_{\rho} d S$

is the net energy input from surface buoyancy forcing.

\section{REFERENCES}

Abernathey, R., and P. Cessi, 2014: Topographic enhancement of eddy efficiency in baroclinic equilibration. J. Phys. Oceanogr., 44, 2107-2126, doi:10.1175/JPO-D-14-0014.1.

_ J. Marshall, and D. Ferreira, 2011: The dependence of Southern Ocean meridional overturning on wind stress. J. Phys. Oceanogr., 41, 2261-2278, doi:10.1175/JPO-D-11-023.1.

Anderson, R. F., S. Ali, L. I. Bradtmiller, S. H. H. Nielsen, M. Q. Fleisher, B. E. Anderson, and L. H. Burckle, 2009: Winddriven upwelling in the Southern Ocean and the deglacial rise in atmospheric $\mathrm{CO}_{2}$. Science, 323, 1443-1448, doi:10.1126/ science. 1167441.

Bishop, S. P., P. R. Gent, F. O. Bryan, A. F. Thompson, M. C. Long, and R. Abernathey, 2016: Southern Ocean overturning compensation in an eddy-resolving climate simulation. J. Phys. Oceanogr., 46, 1575-1592, doi:10.1175/JPO-D-15-0177.1.

Bracegirdle, T. J., E. Shuckburgh, J.-B. Sallée, Z. Wang, A. J. S. Meijers, N. Bruneau, T. Phillips, and L. J. Wilcox, 2013: Assessment of surface winds over the Atlantic, Indian, and Pacific Ocean sectors of the Southern Ocean in CMIP5 models: Historical bias, forcing response, and state dependence. J. Geophys. Res. Atmos., 118, 547-562, doi:10.1002/jgrd.50153.
Broadbridge, M. B., A. C. Naveira Garabato, and A. J. George Nurser, 2016: Forcing of the overturning circulation across a circumpolar channel by internal wave breaking. J. Geophys. Res. Oceans, 121, 5436-5451, doi:10.1002/2015JC011597.

Cheon, W. G., Y.-G. Park, J. R. Toggweiler, and S.-K. Lee, 2014: The relationship of Weddell Polynya and open-ocean deep convection to the Southern Hemisphere westerlies. J. Phys. Oceanogr., 44, 694-713, doi:10.1175/JPO-D-13-0112.1.

Delworth, T. L., and F. Zeng, 2008: Simulated impact of altered Southern Hemisphere winds on the Atlantic meridional overturning circulation. Geophys. Res. Lett., 35, L20708, doi:10.1029/2008GL035166.

_ and Coauthors, 2012: Simulated climate and climate change in the GFDL CM2.5 high-resolution coupled climate model. J. Climate, 25, 2755-2781, doi:10.1175/JCLI-D-11-00316.1.

Dijkstra, H. A., J. A. Saenz, and A. M. Hogg, 2014: Energetics of multidecadal Atlantic Ocean variability. J. Climate, 27, 78747889, doi:10.1175/JCLI-D-12-00801.1.

Döös, K., and D. Webb, 1994: The Deacon cell and the other meridional cells of the Southern Ocean. J. Phys. Oceanogr., 24, 429-442, doi:10.1175/1520-0485(1994)024<0429: TDCATO $>2.0 . \mathrm{CO} ; 2$.

Gent, P. R., 2016: Effects of Southern Hemisphere wind changes on the meridional overturning circulation in ocean models. Annu. Rev. Mar. Sci., 8, 79-94, doi:10.1146/ annurev-marine-122414-033929.

— W. G. Large, and F. O. Bryan, 2001: What sets the mean transport through Drake Passage? J. Geophys. Res., 106, 2693-2712, doi:10.1029/2000JC900036.

Gill, A. E., 1982: Atmosphere-Ocean Dynamics. Academic Press, $662 \mathrm{pp}$.

Griffies, S. M., and Coauthors, 2015: Impacts on ocean heat from transient mesoscale eddies in a hierarchy of climate models. J. Climate, 28, 952-977, doi:10.1175/JCLI-D-14-00353.1.

Heuzé, C., K. J. Heywood, D. P. Stevens, and J. Ridley, 2015: Changes in global ocean bottom properties and volume transports in CMIP5 models under climate change scenarios. J. Climate, 28, 2917-2944, doi:10.1175/JCLI-D-14-00381.1.

Hogg, A. M., H. A. Dijkstra, and J. A. Saenz, 2013: The energetics of a collapsing meridional overturning circulation. J. Phys. Oceanogr., 43, 1512-1524, doi:10.1175/JPO-D-12-0212.1.

Holliday, D., and M. E. McIntyre, 1981: On potential energy density in an incompressible, stratified fluid. J. Fluid Mech., 107, 221-225, doi:10.1017/S0022112081001742.

Howard, E., A. M. Hogg, S. Waterman, and D. P. Marshall, 2015: The injection of zonal momentum by buoyancy forcing in a Southern Ocean model. J. Phys. Oceanogr., 45, 259-271, doi:10.1175/JPO-D-14-0098.1.

Hughes, G. O., A. M. Hogg, and R. W. Griffiths, 2009: Available potential energy and irreversible mixing in the meridional overturning circulation. J. Phys. Oceanogr., 39, 3130-3146, doi:10.1175/2009JPO4162.1.

Ilicak, M., A. J. Adcroft, S. M. Griffies, and R. W. Hallberg, 2012: Spurious dianeutral mixing and the role of momentum closure. Ocean Modell., 45-46, 37-58, doi:10.1016/j.ocemod.2011.10.003.

Jochum, M., and C. Eden, 2015: The connection between Southern Ocean winds, the Atlantic meridional overturning circulation, and Indo-Pacific upwelling. J. Climate, 28, 9250-9257, doi:10.1175/JCLI-D-15-0263.1.

Langlais, C. E., S. R. Rintoul, and J. D. Zika, 2015: Sensitivity of Antarctic Circumpolar Current transport and eddy activity to wind patterns in the Southern Ocean. J. Phys. Oceanogr., 45, 1051-1067, doi:10.1175/JPO-D-14-0053.1. 
Large, W. G., and S. G. Yeager, 2009: The global climatology of an interannually varying air-sea flux data set. Climate Dyn., 33, 341-364, doi:10.1007/s00382-008-0441-3.

Lauderdale, J. M., A. C. N. Garabato, K. I. C. Oliver, M. J. Follows, and R. G. Williams, 2013: Wind-driven changes in Southern Ocean residual circulation, ocean carbon reservoirs and atmospheric $\mathrm{CO}_{2}$. Climate Dyn., 41, 2145-2164, doi:10.1007/ s00382-012-1650-3.

Le Quéré, C., and Coauthors, 2007: Saturation of the Southern Ocean $\mathrm{CO}_{2}$ sink due to recent climate change. Science, $\mathbf{3 1 6}$ 1735-1738, doi:10.1126/science.1136188.

Lumpkin, R., and K. Speer, 2007: Global ocean meridional overturning. J. Phys. Oceanogr., 37, 2550-2562, doi:10.1175/ JPO3130.1.

Marshall, J., and T. Radko, 2003: Residual-mean solutions for the Antarctic Circumpolar Current and its associated overturning circulation. J. Phys. Oceanogr., 33, 2341-2354, doi:10.1175/ 1520-0485(2003)033<2341:RSFTAC $>2.0 . C O ; 2$.

— , and K. Speer, 2012: Closure of the meridional overturning circulation through Southern Ocean upwelling. Nat. Geosci., 5, 171-180, doi:10.1038/ngeo1391.

Meredith, M. P., A. C. Naveira Garabato, A. M. Hogg, and R. Farneti, 2012: Sensitivity of the overturning circulation in the Southern Ocean to decadal changes in wind forcing. J. Climate, 25, 99-110, doi:10.1175/2011JCLI4204.1.

Molemaker, M. J., and J. C. McWilliams, 2010: Local balance and cross-scale flux of available potential energy. J. Fluid Mech. 645, 295-314, doi:10.1017/S0022112009992643.

Morrison, A. K., and A. M. Hogg, 2013: On the relationship between Southern Ocean overturning and ACC transport J. Phys. Oceanogr., 43, 140-148, doi:10.1175/JPO-D-12-057.1.

,-- , and M. L. Ward, 2011: Sensitivity of the Southern Ocean overturning circulation to surface buoyancy forcing. Geophys. Res. Lett., 38, L14602, doi:10.1029/2011GL048031.

_, T. L. Frölicher, and J. L. Sarmiento, 2015: Upwelling in the Southern Ocean. Phys. Today, 68, 27-32, doi:10.1063/ PT.3.2654.

Nikurashin, M., and R. Ferrari, 2013: Overturning circulation driven by breaking internal waves in the deep ocean. Geophys. Res. Lett., 40, 3133-3137, doi:10.1002/grl.50542.

Nurser, A., and M. M. Lee, 2004: Isopycnal averaging at constant height. Part I: The formulation and a case study. J. Phys. Oceanogr., 34, 2721-2739, doi:10.1175/JPO2649.1.

Nycander, J., J. Nilsson, K. Döös, and G. Broström, 2007: Thermodynamic analysis of ocean circulation. J. Phys. Oceanogr., 37, 2038-2052, doi:10.1175/JPO3113.1.

Roullet, G., and P. Klein, 2009: Available potential energy diagnosis in a direct numerical simulation of rotating stratified turbulence. J. Fluid Mech., 624, 45-55, doi:10.1017/ S0022112008004473.

Saenz, J. A., R. Tailleux, E. D. Butler, G. O. Hughes, and K. I. C. Oliver, 2015: Estimating Lorenz's reference state in an ocean with a nonlinear equation of state for seawater. J. Phys. Oceanogr., 45, 1242-1257, doi:10.1175/JPO-D-14-0105.1.

Snow, K., A. M. Hogg, B. M. Sloyan, and S. M. Downes, 2016: Sensitivity of Antarctic Bottom Water to changes in surface buoyancy fluxes. J. Climate, 29, 313-330, doi:10.1175/ JCLI-D-15-0467.1.
Spence, P., S. M. Griffies, M. H. England, A. M. Hogg, O. A. Saenko, and N. C. Jourdain, 2014: Rapid subsurface warming and circulation changes of Antarctic coastal waters by poleward shifting winds. Geophys. Res. Lett., 41, 4601-4610, doi:10.1002/2014GL060613.

Stanley, G. J., and O. A. Saenko, 2014: Bottom-enhanced diapycnal mixing driven by mesoscale eddies: Sensitivity to wind energy supply. J. Phys. Oceanogr., 44, 68-85, doi:10.1175/ JPO-D-13-0116.1.

Stewart, K. D., J. A. Saenz, A. M. Hogg, G. O. Hughes, and R. W. Griffiths, 2014: Effect of topographic barriers on the rates of available potential energy conversion of the oceans. Ocean Modell., 76, 31-42, doi:10.1016/j.ocemod.2014.02.001.

Tailleux, R., 2013: Available potential energy density for a multicomponent Boussinesq fluid with arbitrary nonlinear equation of state. J. Fluid Mech., 735, 499-518, doi:10.1017/ jfm.2013.509.

Tamura, T., K. I. Ohshima, A. D. Fraser, and G. D. Williams, 2016: Sea ice production variability in Antarctic coastal polynyas. J. Geophys. Res. Oceans, 121, 2967-2979, doi:10.1002/ 2015 JC011537.

Thompson, D. W. J., and S. Solomon, 2002: Interpretation of recent Southern Hemisphere climate change. Science, 296, 895-899, doi:10.1126/science.1069270.

Toggweiler, J. R., and B. Samuels, 1998: On the ocean's large-scale circulation near the limit of no vertical mixing. J. Phys. Oceanogr., 28, 1832-1852, doi:10.1175/1520-0485(1998)028<1832: OTOSLS $>2.0 . \mathrm{CO} ; 2$.

_ J. L. Russell, and S. R. Carson, 2006: Midlatitude westerlies, atmospheric $\mathrm{CO}_{2}$, and climate change during the ice ages. Paleoceanography, 21, PA2005, doi:10.1029/2005PA001154.

Urakawa, L. S., J. A. Saenz, and A. M. Hogg, 2013: Available potential energy gain from mixing due to the nonlinearity of the equation of state in a global ocean model. Geophys. Res. Lett., 40, 2224-2228, doi:10.1002/grl.50508.

Viebahn, J., and C. Eden, 2010: Towards the impact of eddies on the response of the Southern Ocean to climate change. Ocean Modell., 34, 150-165, doi:10.1016/j.ocemod.2010.05.005.

— , and - 2012: Standing eddies in the meridional overturning circulation. J. Phys. Oceanogr., 42, 1486-1508, doi:10.1175/JPO-D-11-087.1.

Winters, K. B., and R. Barkan, 2013: Available potential energy density for Boussinesq fluid flow. J. Fluid Mech., 714, 476-488, doi:10.1017/jfm.2012.493.

— , P. N. Lombard, J. J. Riley, and E. A. D’Asaro, 1995: Available potential energy and mixing in density-stratified fluids. J. Fluid Mech., 289, 115-128, doi:10.1017/S002211209500125X.

Wolfe, C. L., and P. Cessi, 2011: The adiabatic pole-to-pole overturning circulation. J. Phys. Oceanogr., 41, 1795-1810, doi:10.1175/2011JPO4570.1.

Zheng, F., J. Li, R. T. Clark, and H. C. Nnamchi, 2013: Simulation and projection of the Southern Hemisphere annular mode in CMIP5 models. J. Climate, 26, 9860-9879, doi:10.1175/ JCLI-D-13-00204.1.

Zika, J. D., and Coauthors, 2013: Vertical eddy fluxes in the Southern Ocean. J. Phys. Oceanogr., 43, 941-955, doi:10.1175/ JPO-D-12-0178.1. 